\title{
Antimicrobial stewardship in rural and remote primary health care: a narrative review
}

Jun Wern Yau ${ }^{1 \dagger}$, Sze Mun Thor ${ }^{1 \dagger}$, Danny Tsai ${ }^{2,3,4}$, Tobias Speare ${ }^{2,3}$ and Chris Risse $2^{2^{*}}$ (D)

\begin{abstract}
Background: Antimicrobial resistance is an emerging problem worldwide and poses a significant threat to human health. Antimicrobial stewardship programmes are being implemented in health systems globally, primarily in hospitals, to address the growing threat of antimicrobial resistance. Despite the significance of primary health care services in providing health care to communities, antimicrobial stewardship programmes are not well established in this sector, especially in rural and remote settings. This narrative review aims to identify in rural and remote primary health care settings the (1) correlation of antimicrobial resistance with antibiotic prescribing and volume of antibiotic use, (2) appropriateness of antimicrobial prescribing, (3) risk factors associated with inappropriate use/prescribing of antibiotics, and (4) effective antimicrobial stewardship strategies.
\end{abstract}

Methods: The international literature was searched for English only articles between 2000 and 2020 using specified keywords. Seven electronic databases were searched: Scopus, Cochrane, Embase, CINAHL, PubMed, Ovid Medline and Ovid Emcare. Publication screening and analysis were conducted using Joanna Briggs Institute systematic review tools.

Results: Fifty-one eligible articles were identified. Inappropriate and excessive antimicrobial prescribing and use directly led to increases in antimicrobial resistance. Increasing rurality of practice is associated with disproportionally higher rates of inappropriate prescribing compared to those in metropolitan areas. Physician knowledge, attitude and behaviour play important roles in mediating antimicrobial prescribing, with strong intrinsic and extrinsic influences including patient factors. Antimicrobial stewardship strategies in rural and remote primary health care settings focus on health care provider and patient education, clinician support systems, utility of antimicrobial resistance surveillance, and policy changes. Results of these interventions were generally positive with decreased antimicrobial resistance rates and improved appropriateness of antimicrobial prescribing.

Conclusions: Inappropriate prescribing and excessive use of antimicrobials are an important contributor to the increasing resistance towards antimicrobial agents particularly in rural and remote primary health care. Antimicrobial stewardship programmes in the form of education, clinical support, surveillance, and policies have been mostly successful in reducing prescribing rates and inappropriate prescriptions. The narrative review highlighted the need for longer interventions to assess changes in antimicrobial resistance rates. The review also identified a lack

\footnotetext{
*Correspondence: chris.rissel@flinders.edu.au

†Jun Wern Yau and Sze Mun Thor shared first authors

${ }^{2}$ Flinders University- Rural and Remote Health NT, Royal Darwin Hospital

Campus, Rocklands Drive, Tiwi, NT 0810, Australia

Full list of author information is available at the end of the article
} permits use, sharing, adaptation, distribution and reproduction in any medium or format, as long as you give appropriate credit to the original author(s) and the source, provide a link to the Creative Commons licence, and indicate if changes were made. The images or other third party material in this article are included in the article's Creative Commons licence, unless indicated otherwise in a credit line to the material. If material is not included in the article's Creative Commons licence and your intended use is not permitted by statutory regulation or exceeds the permitted use, you will need to obtain permission directly from the copyright holder. To view a copy of this licence, visit http://creativecommons.org/licenses/by/4.0/. The Creative Commons Public Domain Dedication waiver (http://creativeco mmons.org/publicdomain/zero/1.0/) applies to the data made available in this article, unless otherwise stated in a credit line to the data. 
of differentiation between rural and remote contexts and Indigenous health was inadequately addressed. Future research should have a greater focus on effective interventional components and patient perspectives.

Keywords: Antimicrobial stewardship, Inappropriate prescribing, Antimicrobial resistance, Antimicrobial, Bacterial, Primary health care, Anti-infective agents, Rural health, Health education, Public health surveillance

\section{Background}

Antimicrobials are pharmaceutical agents used to destroy or halt the growth of pathogenic microorganisms and are an integral part of health care. The effectiveness of antimicrobials against a variety of pathogens has been decreasing at alarming rates due to developing antimicrobial resistance (AMR) [1]. Antimicrobial resistance is a global health concern that contributes to patient morbidity and mortality and increases the cost of health care [2]. It has been recognised as one of the most significant health challenges of the present and future, generating global and national responses [3-6].

Antimicrobial stewardship (AMS) programmes combat the rise of AMR through evidence-based multicomponent strategies, including AMR surveillance, education, and guidance to encourage judicious antimicrobial use, to improve health outcomes [7, 8]. AMS programmes are well established in hospital settings, being introduced more than 30 years ago [9]. The implementation of AMS programmes in primary health care (PHC) settings is less well established due in part to additional challenges, including shortages of healthcare professionals and less access to therapeutic tools $[10,11]$. Most of the research into effectiveness and implementation of AMS strategies is based in hospital settings. There is a gap in the understanding of how AMS programmes best work in PHC settings, particularly in the rural and remote context.

Around the world, the health of people in rural and remote areas tends to be worse than people in urban centres [12]. 'Rural' and 'remote' are often use synonymously, however it is important to recognise that these terms describe distinct contexts with differing models of health care [13]. The rurality or remoteness of a location is determined on the basis of geographic remoteness to population centres and relative access to services, which incorporates size of population centres, road distances, integrity of transport infrastructure, and the types and availability of goods and services [14, 15]. While there are different scales to measure remoteness around the world, in the Australian health care context the Modified Monash Model (MMM) considers MMM 4 and 5 as rural and MMM 6 and 7 considered remote and very remote. For example, MMM 4 includes a location in, or within $10 \mathrm{~km}$ road distance, of a town with a population between 5000 and 15,000 [14]. The criteria used to define 'remote' is a combination of smaller population size, greater road distances to services and other factors, with an exact classification a technical combination of variables [14]. Populations in remote areas tend to be sicker and more dispersed, there are greater workforce shortages, the delivery of health care more costly, and a greater proportion of the population is Indigenous [16]. As the distance from major cities increases, death rates increase, access to health services decline and rates of preventable hospitalisations for chronic diseases markedly rise [17-19]. Recent publications have identified the significant burden of infections and antimicrobial use in remote Australian committees and an upward trend of AMR [11, $20,21]$.

This narrative review aims to identify the evidence of the emergence of AMR associated with antimicrobial use and the effectiveness of AMS interventions in the rural and remote PHC setting. There are four objectives of this review: to describe the correlation of AMR with antibiotic prescribing and/or volume of antibiotic use; describe the appropriateness of antimicrobial prescribing in rural and remote PHC; identify risk factors associated with inappropriate use/prescribing of antibiotics; and describe effective AMS strategies in rural and remote PHC settings.

\section{Methods}

Searches were conducted in seven online databases: Scopus, Cochrane, Embase, CINAHL, PubMed, Ovid Medline and Ovid Emcare. Keywords and Boolean operators employed were ('antimicrobial prescribing' OR 'antimicrobial resistance' OR 'antimicrobial stewardship') AND ('primary health care' OR 'primary healthcare' OR 'primary care' OR 'indigenous' OR 'aboriginal') AND ('rural' OR 'remote'). Only English language articles published between 2000 and 2020 were included to capture studies with greater relevance to current clinical practice and are suitable for thorough analysis.

Records retrieved were independently examined by two authors (JWY and SMT). After the initial selection process, the two authors jointly screened all selected articles and discussed the eligibility of inclusion in this review. Studies which did not feature a remote or rural target group or deemed extraneous were excluded by title and abstract, followed by a full-text review (Fig. 1). Further manual searching for additional relevant articles were 


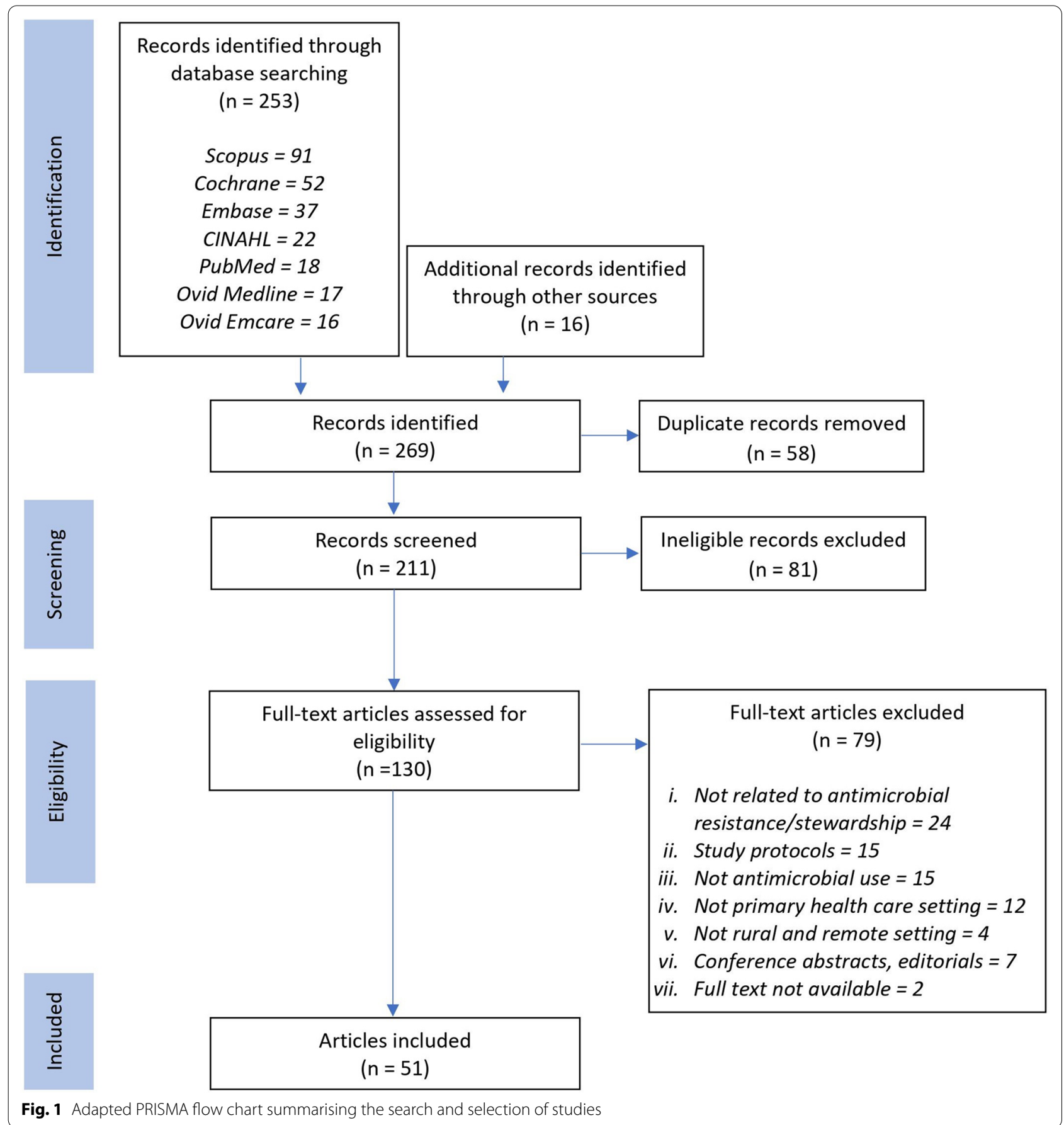

performed by checking the reference lists of included studies as well as key scientific texts and source materials.

Data extracted from the included studies were study design, country of research, population under investigation and findings. The main findings were summarised. Additionally, descriptions of interventions and their measured outcomes were included for studies investigating AMS strategies. Subsequently, studies were grouped into four main themes to address the objectives of the review. Key extraction data of each study can be found in Tables 1, 2, 3 and 4. Several studies found to be relevant to more than one theme were categorised in two or more tables. Critical appraisal was performed for all studies using checklists by the Joanna Briggs Institute (JBI), with results classified in Additional file 1: Tables S1-S8. Ethics approval was not sought given that all material used was publicly available and previously published data. 


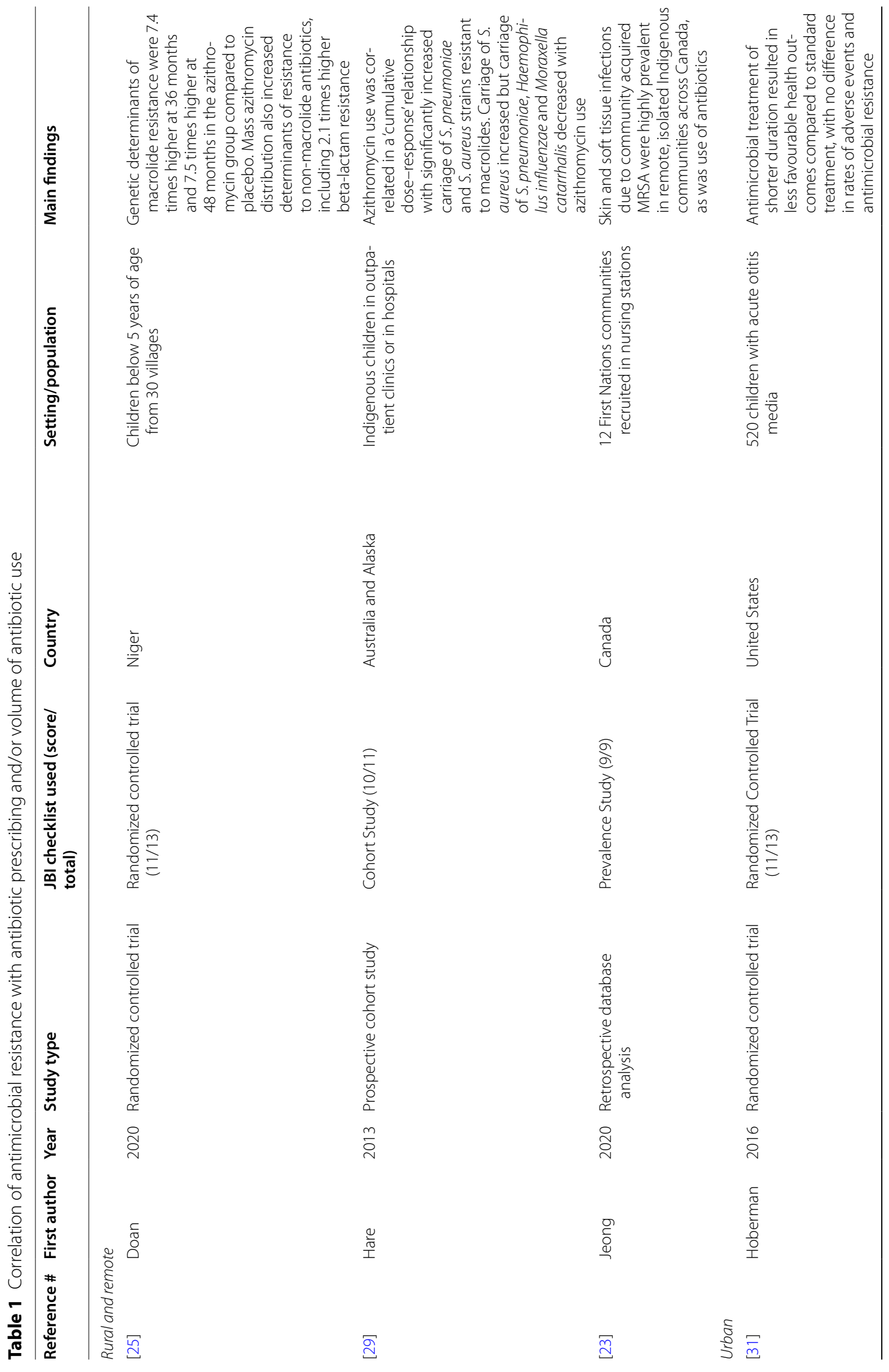




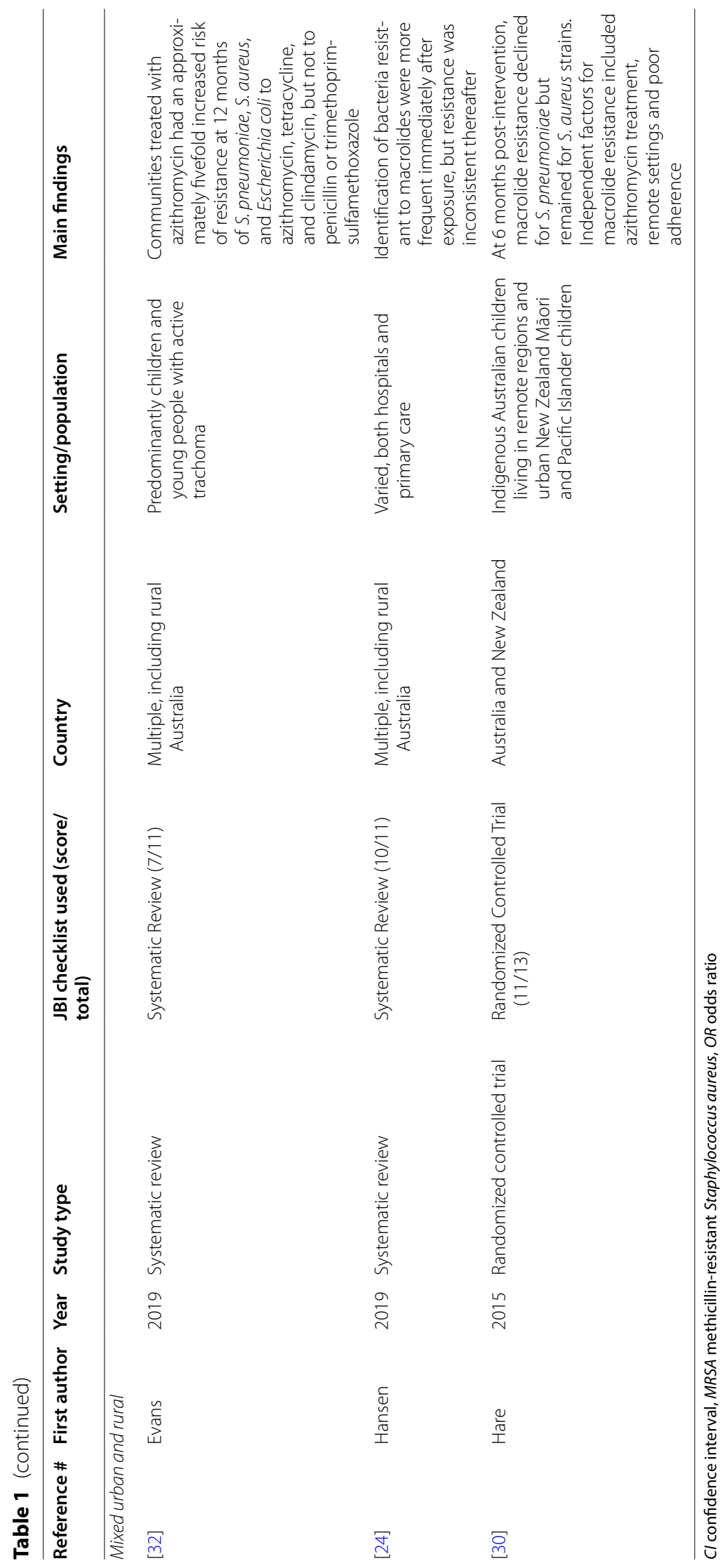




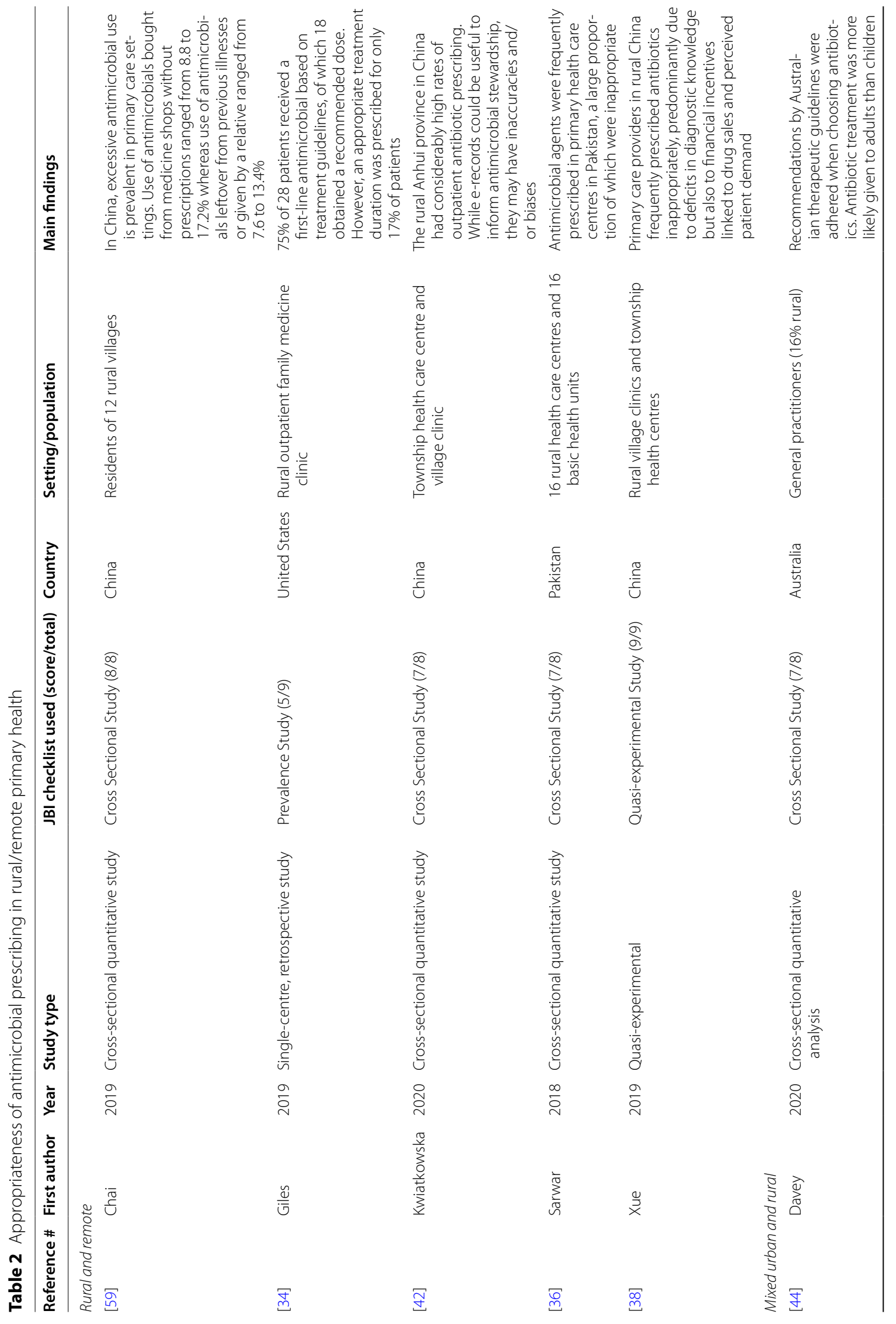




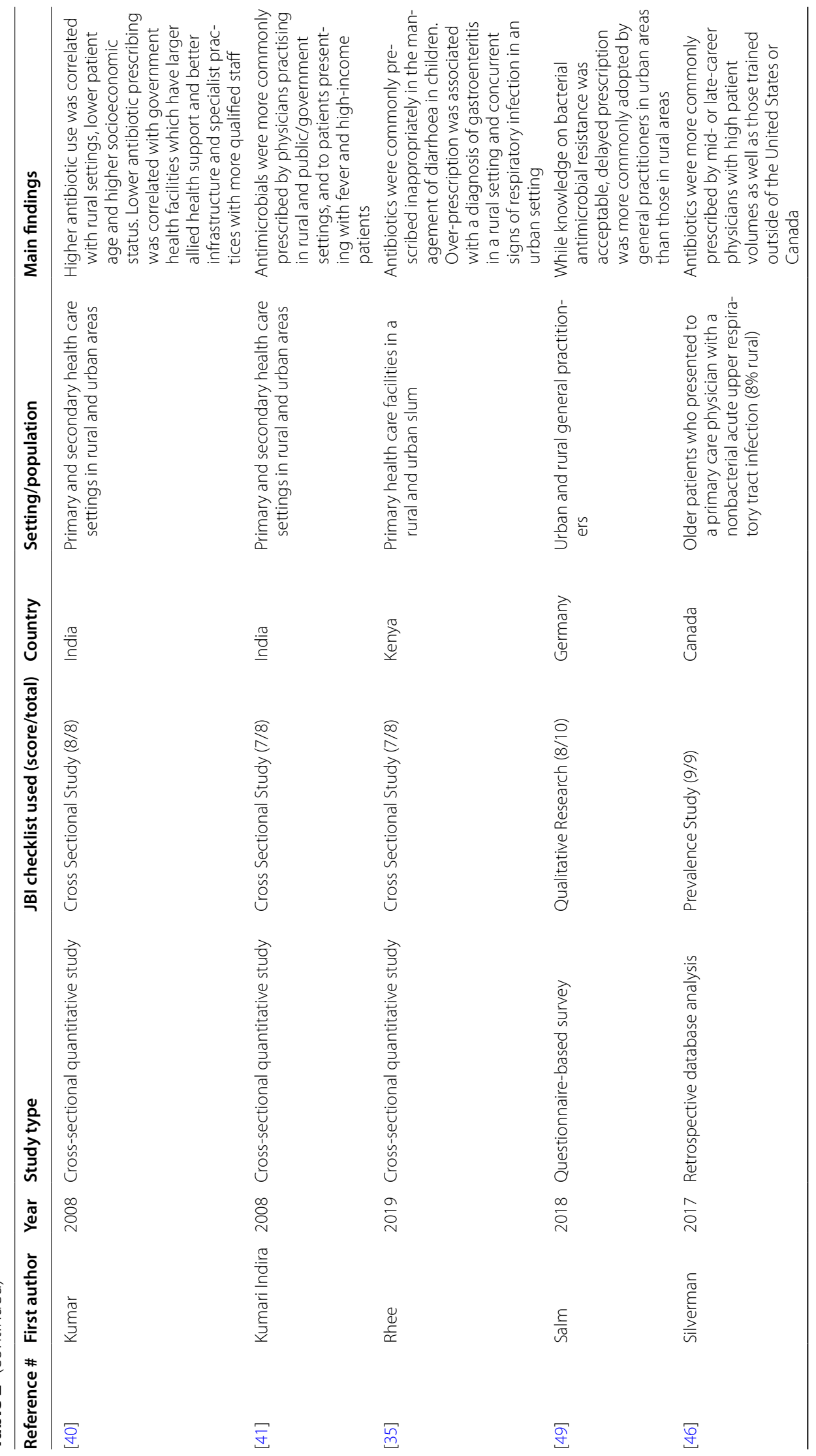




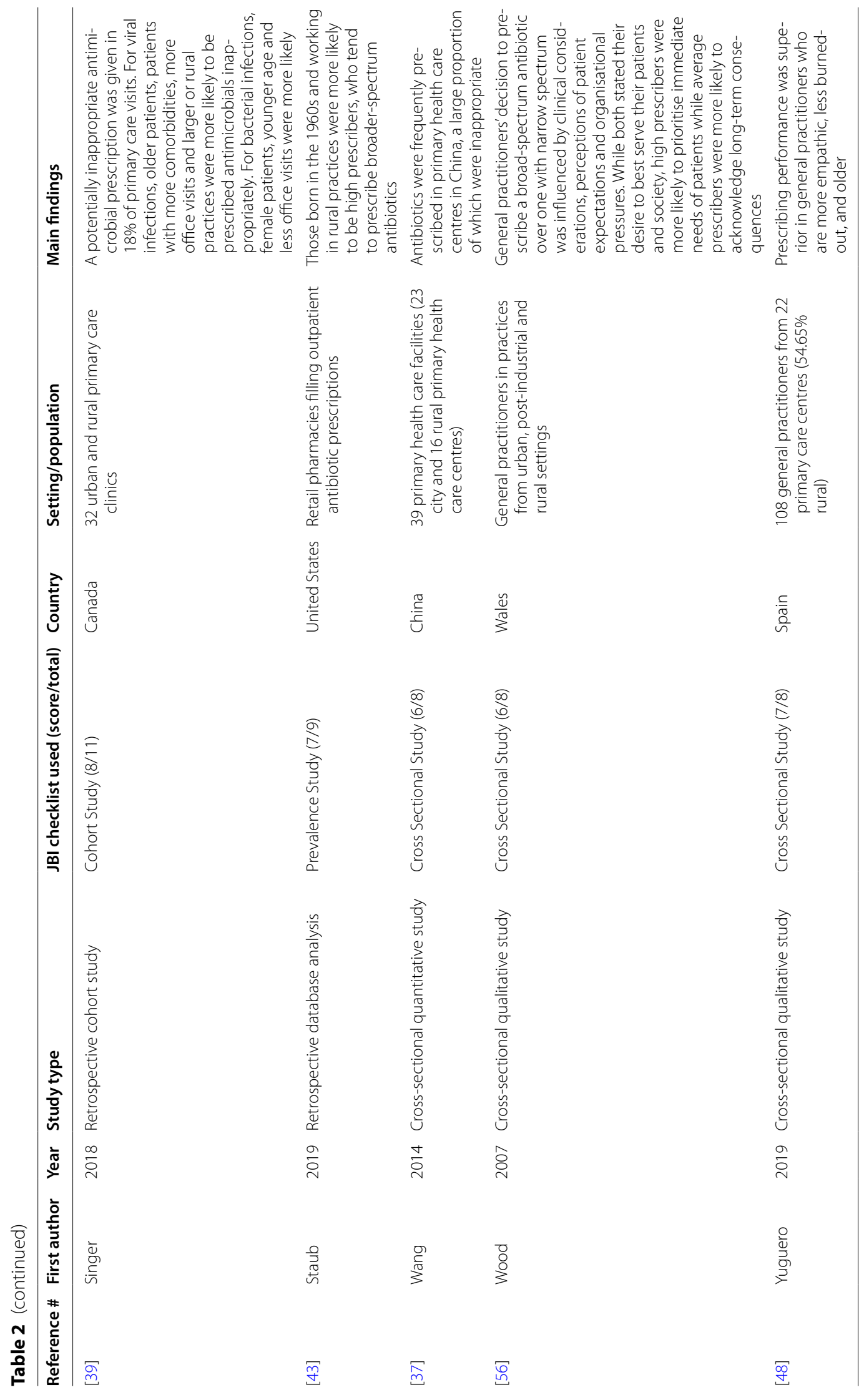




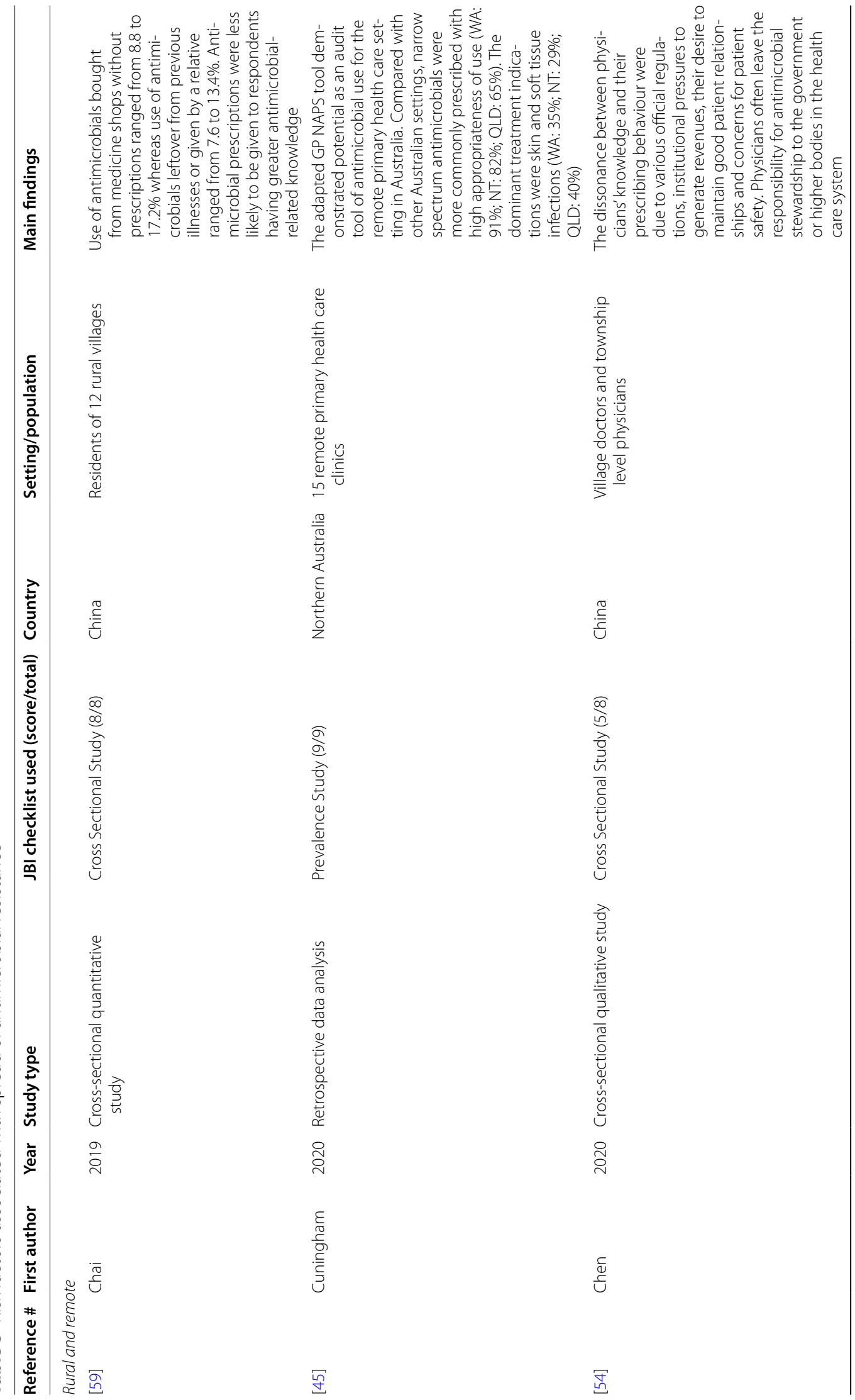




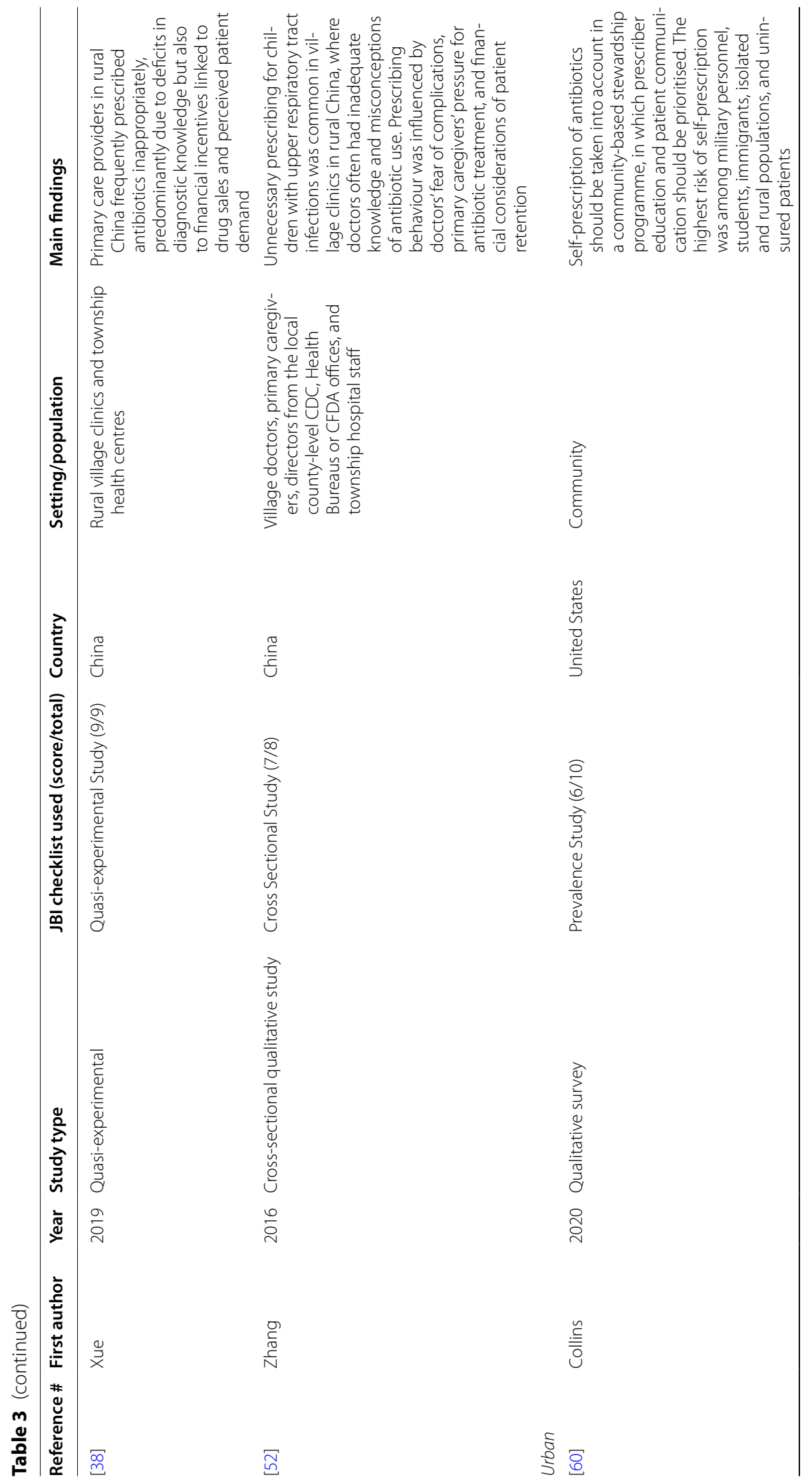




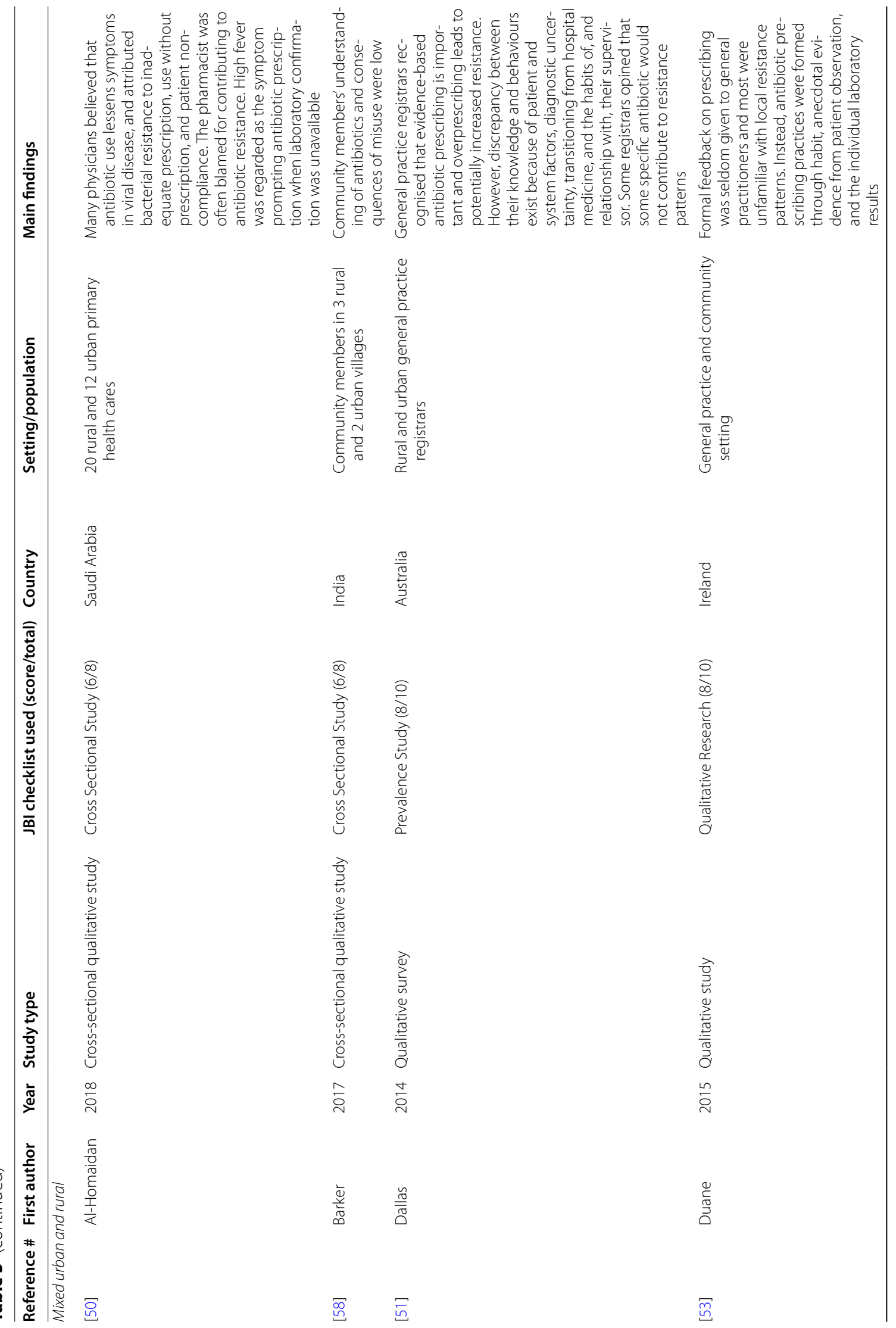




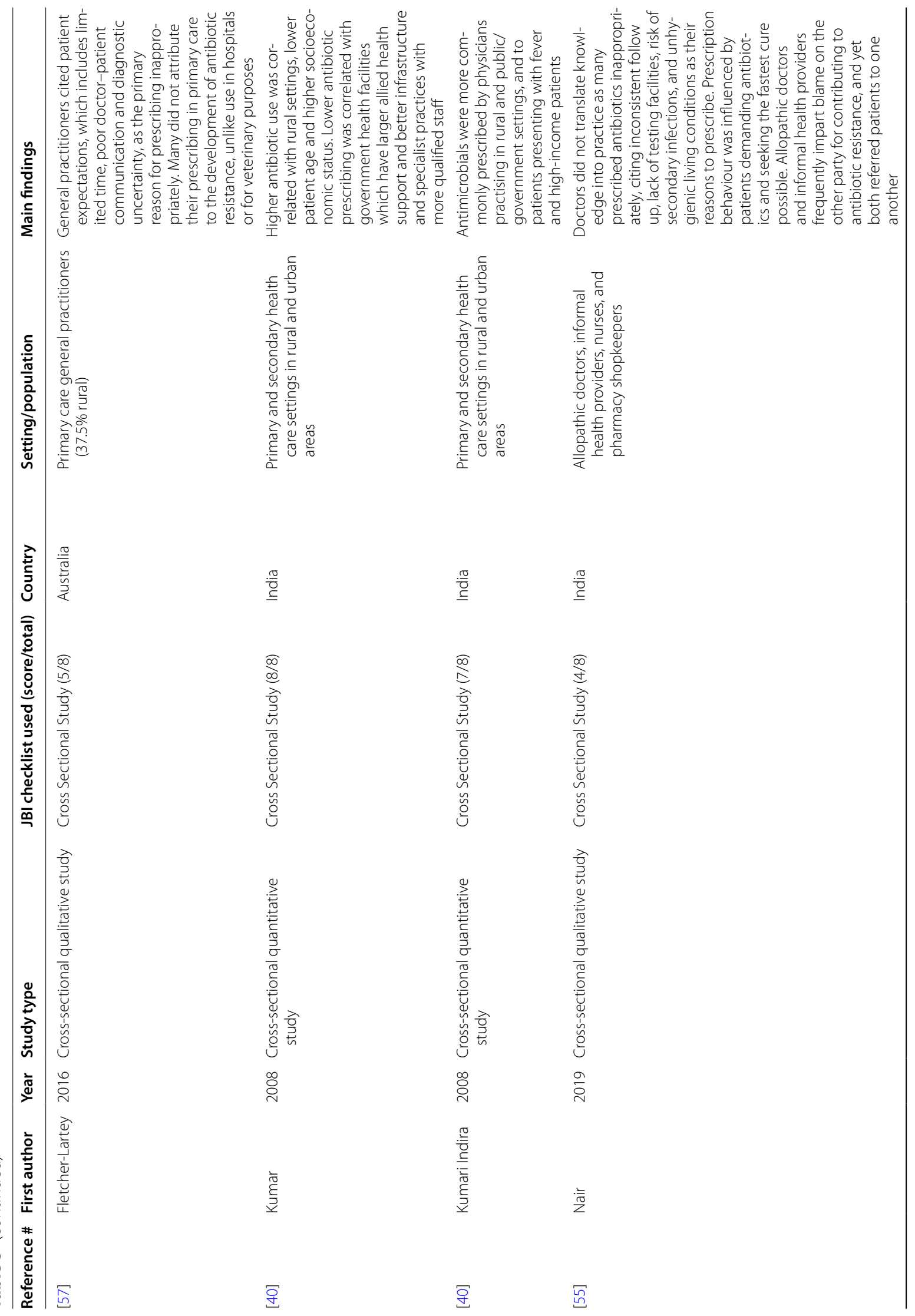




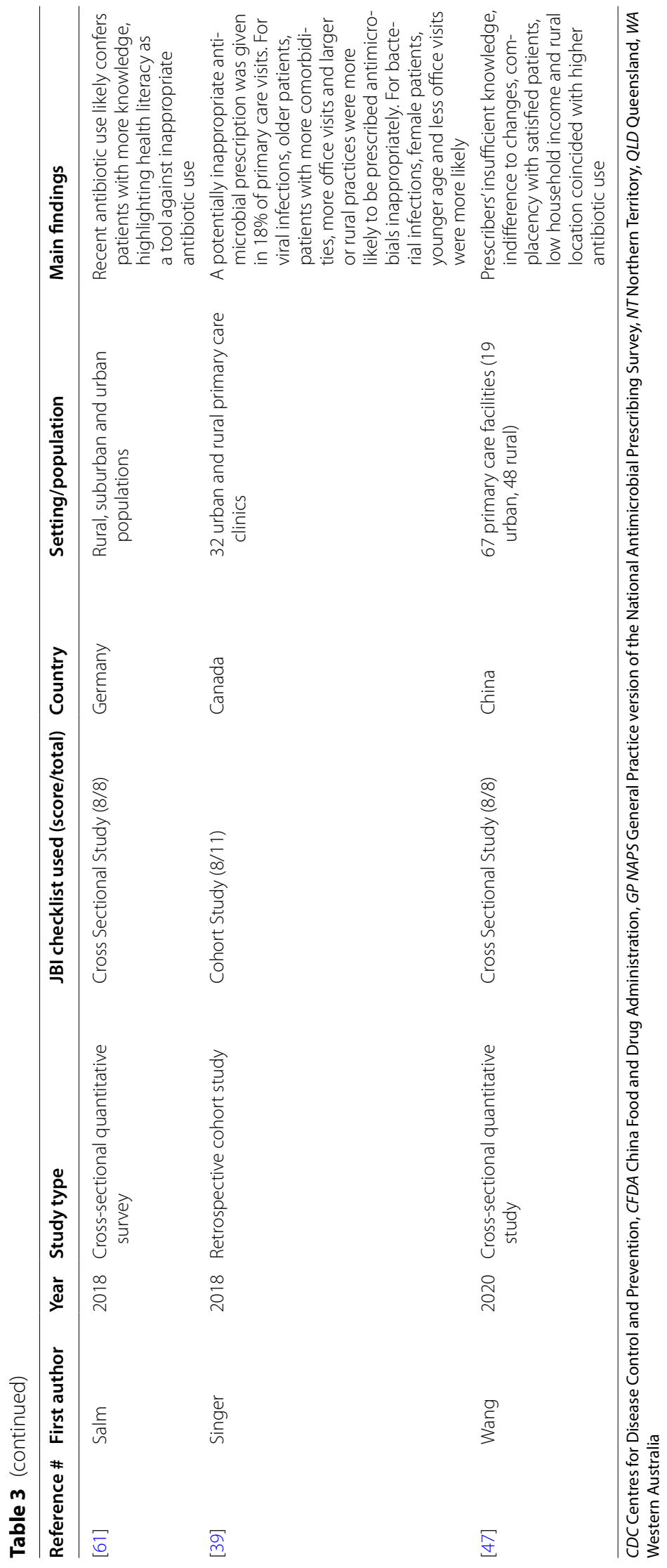




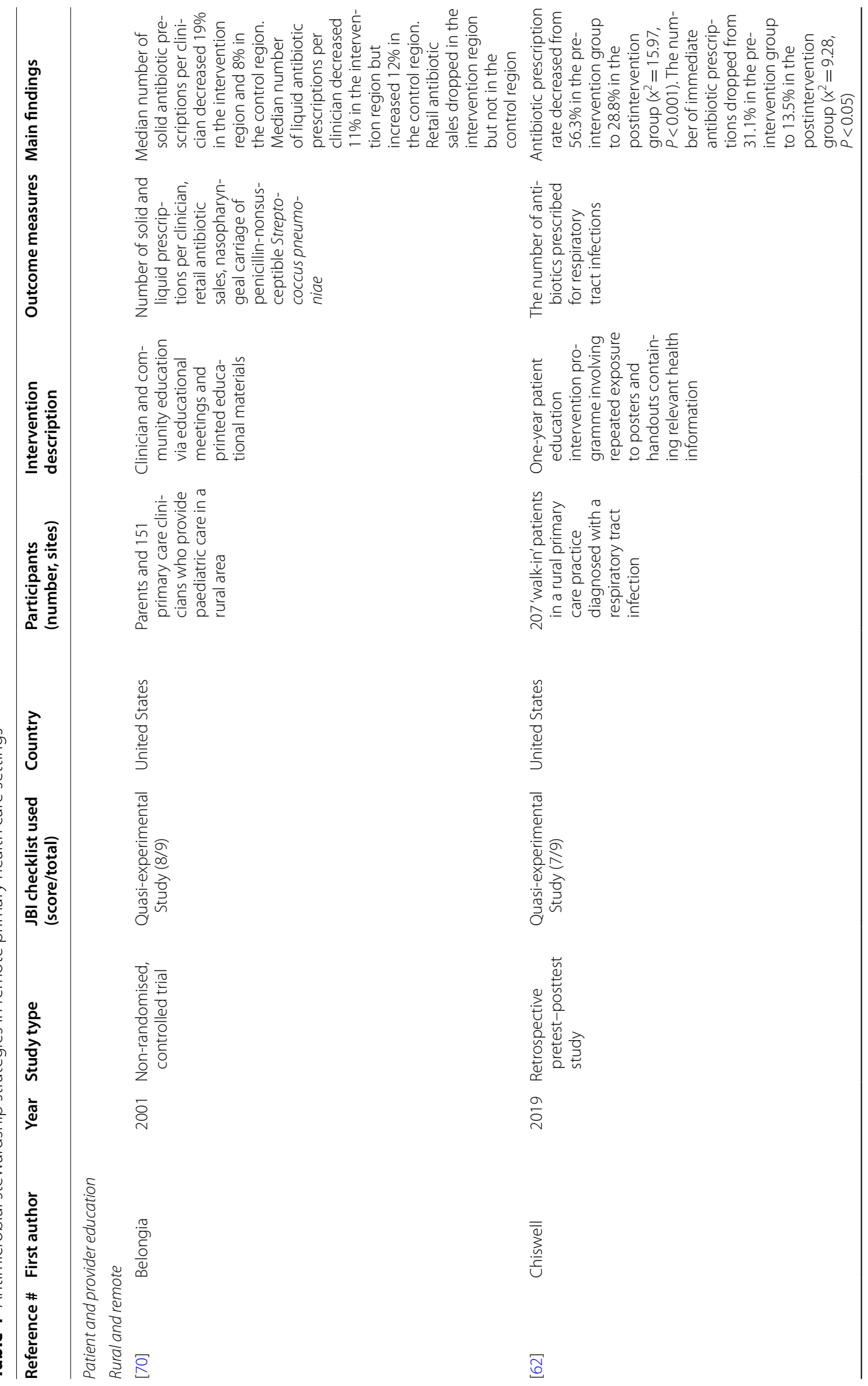




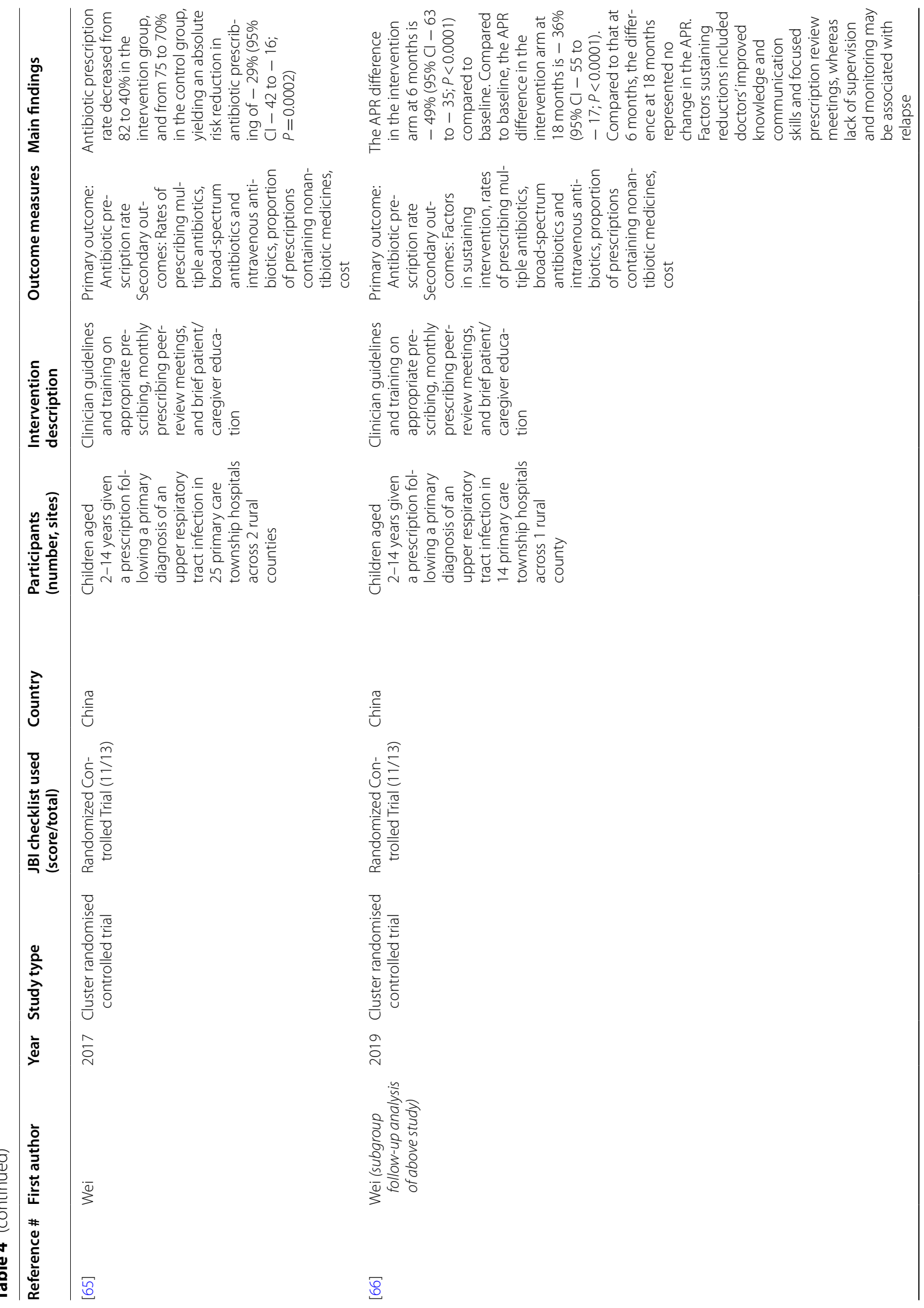




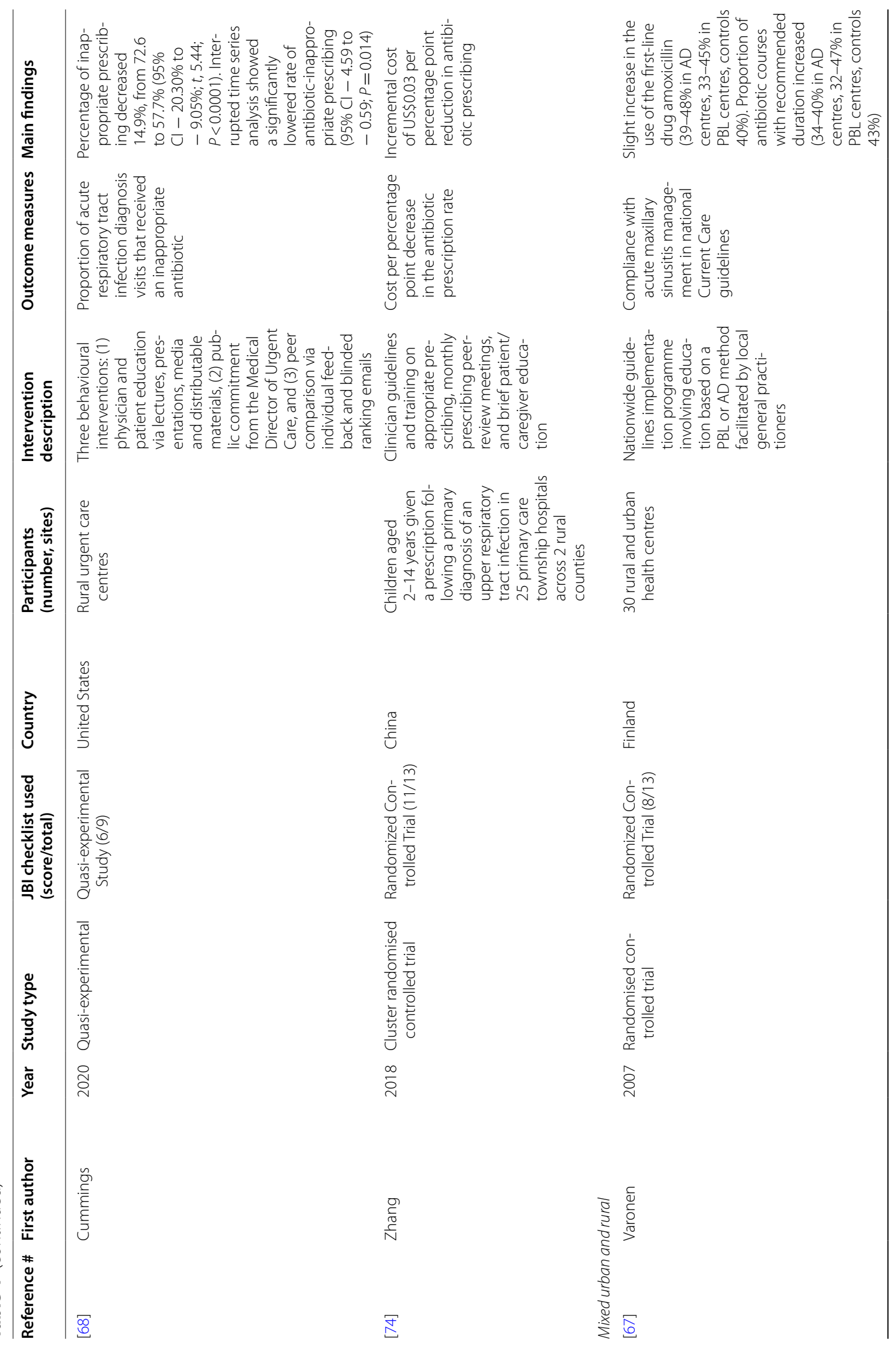




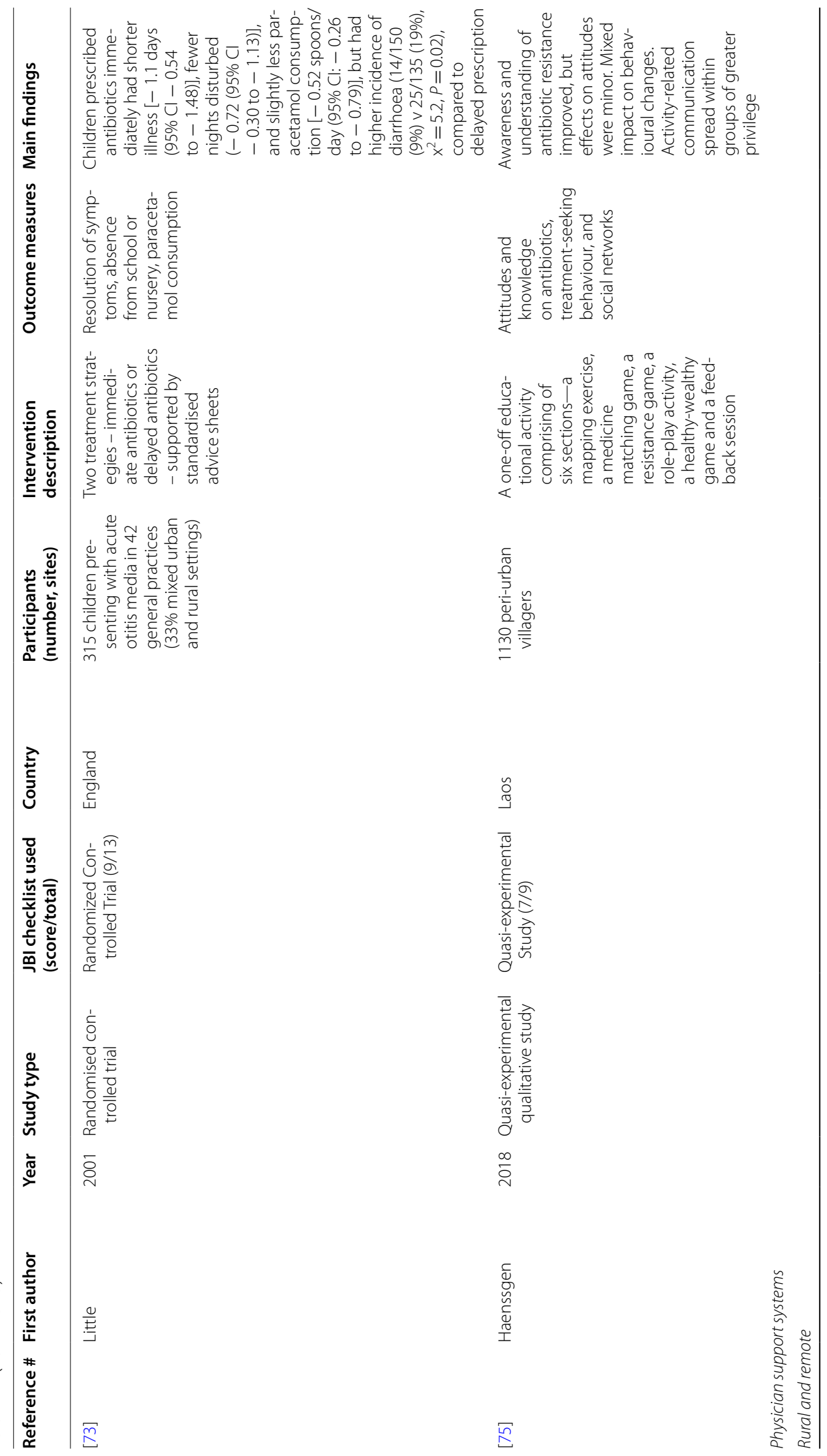




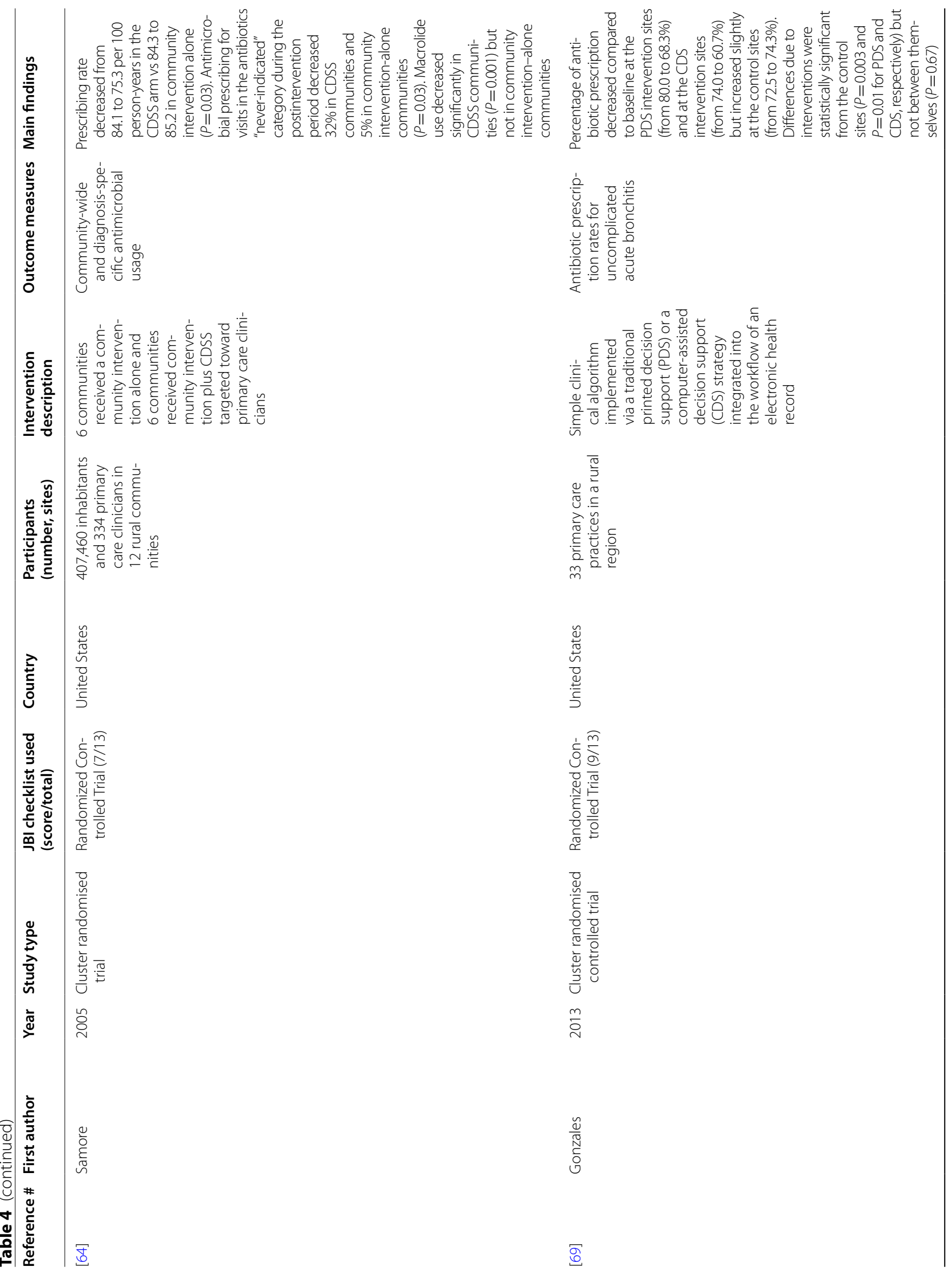




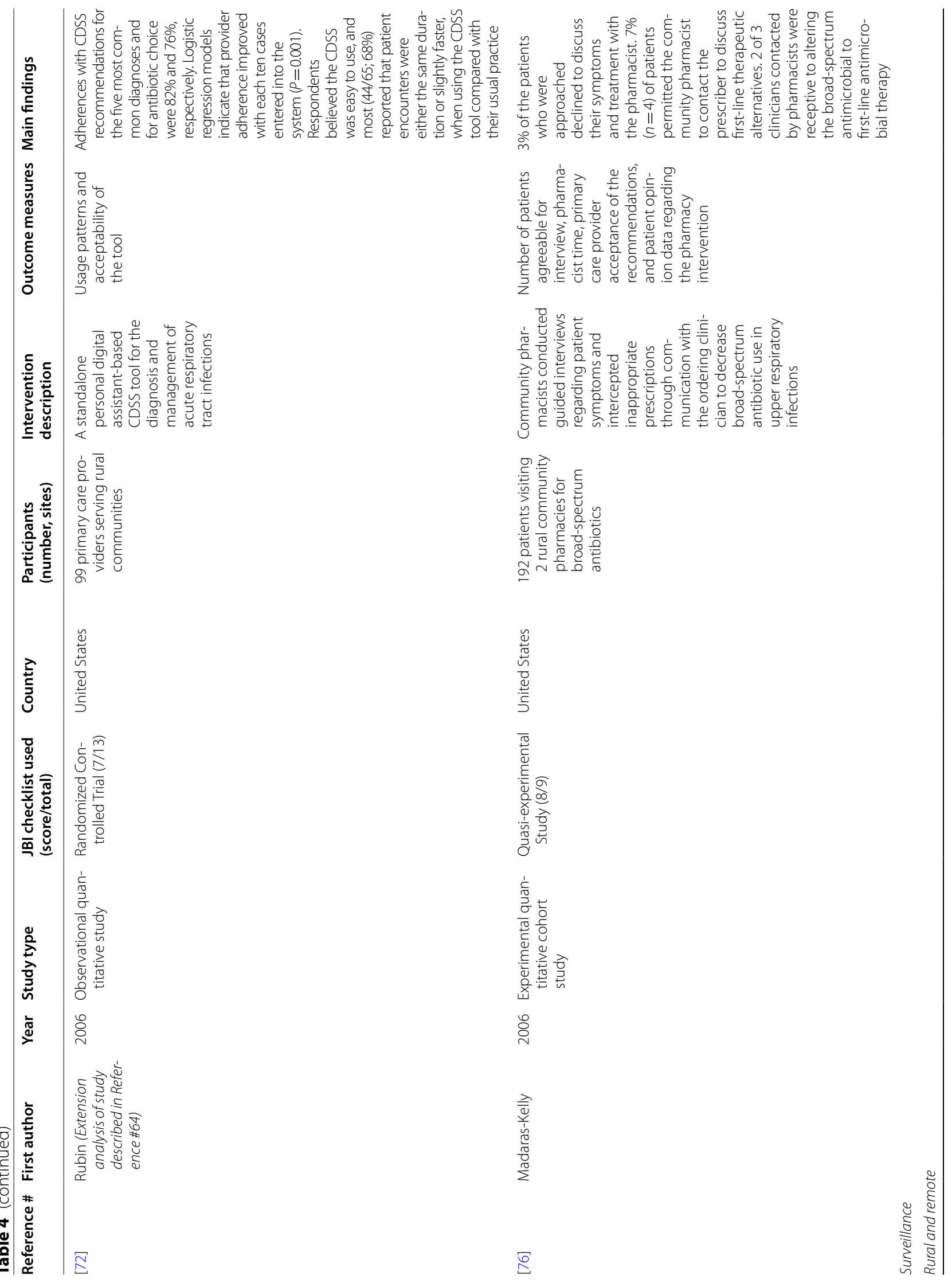




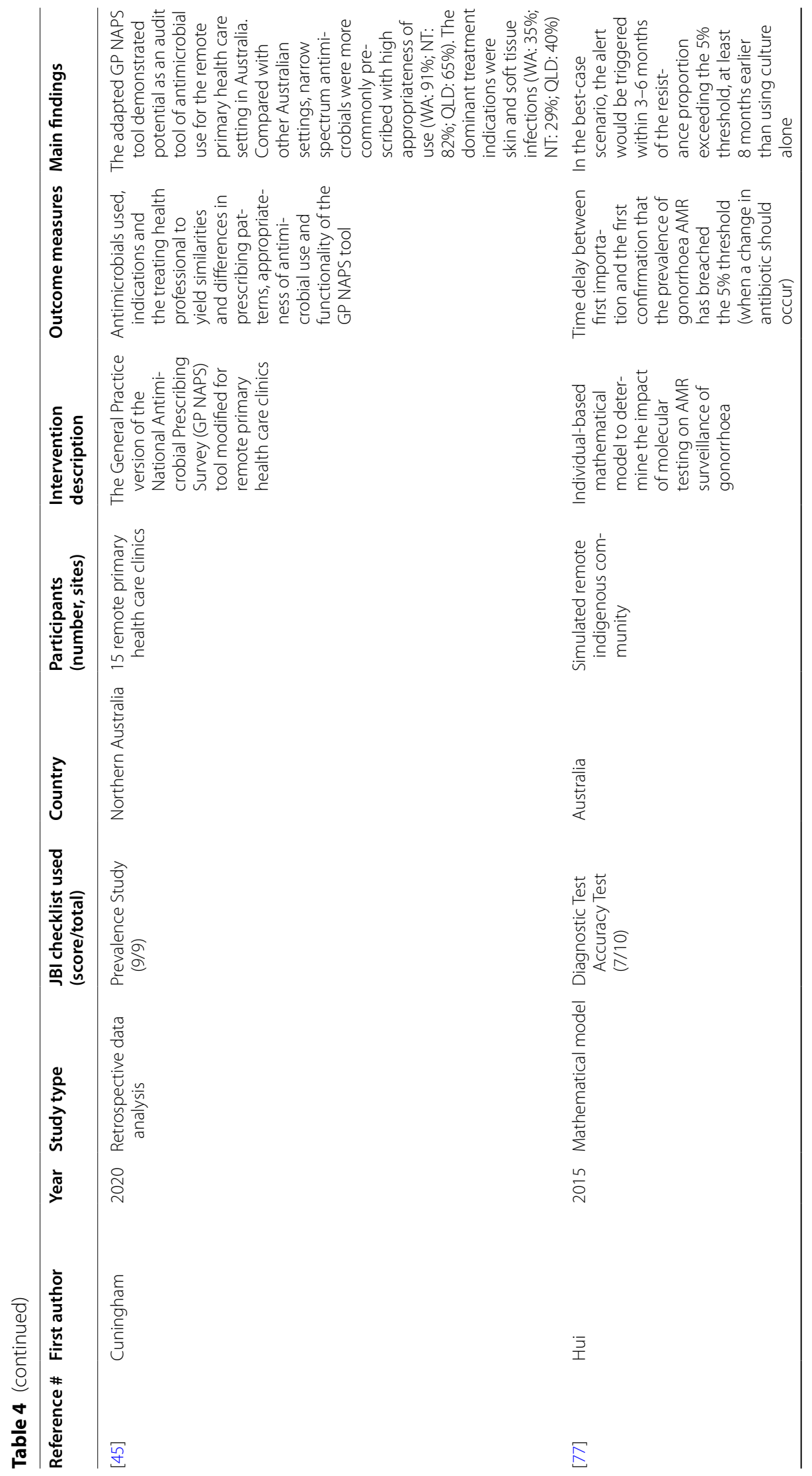




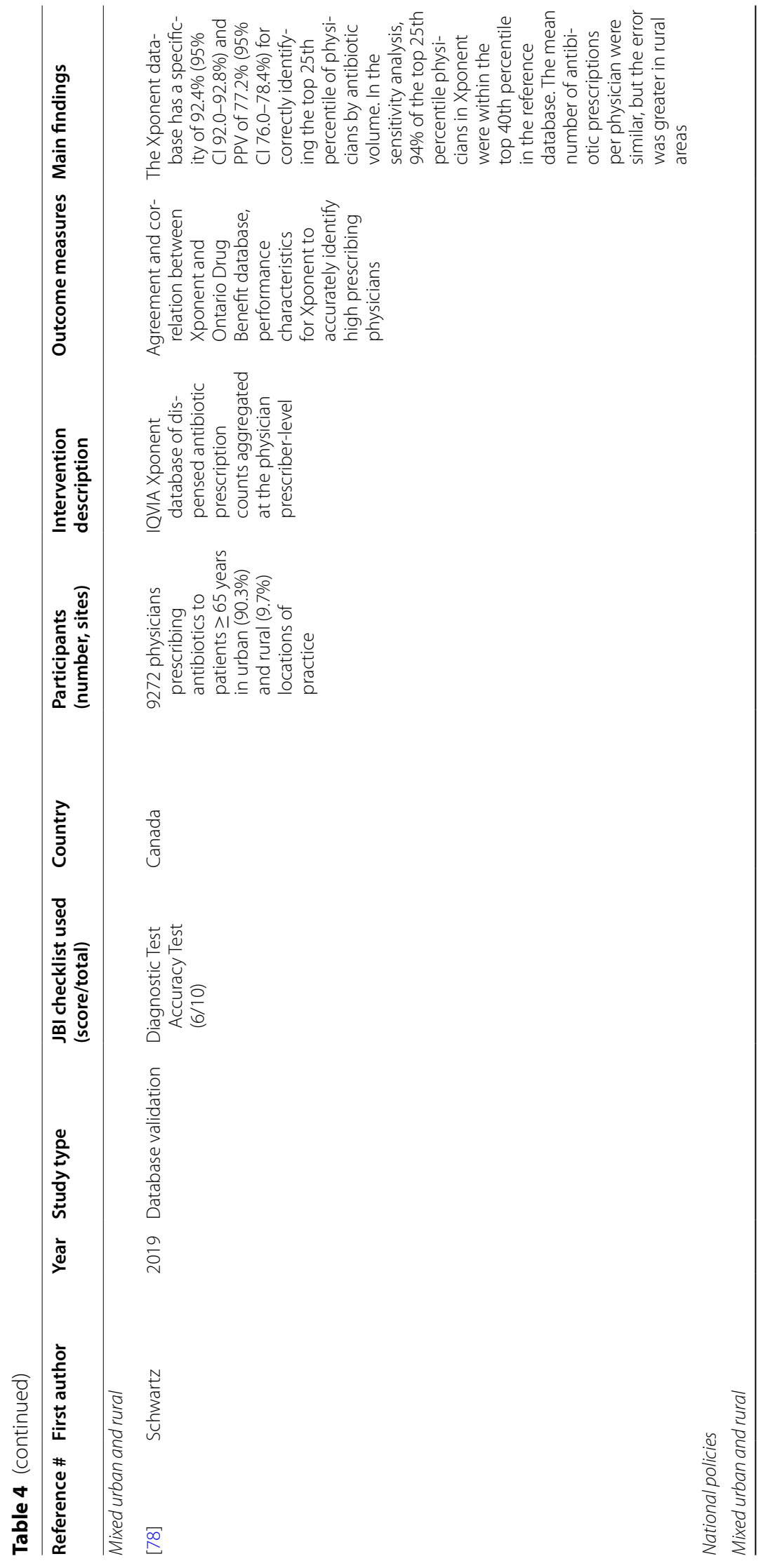




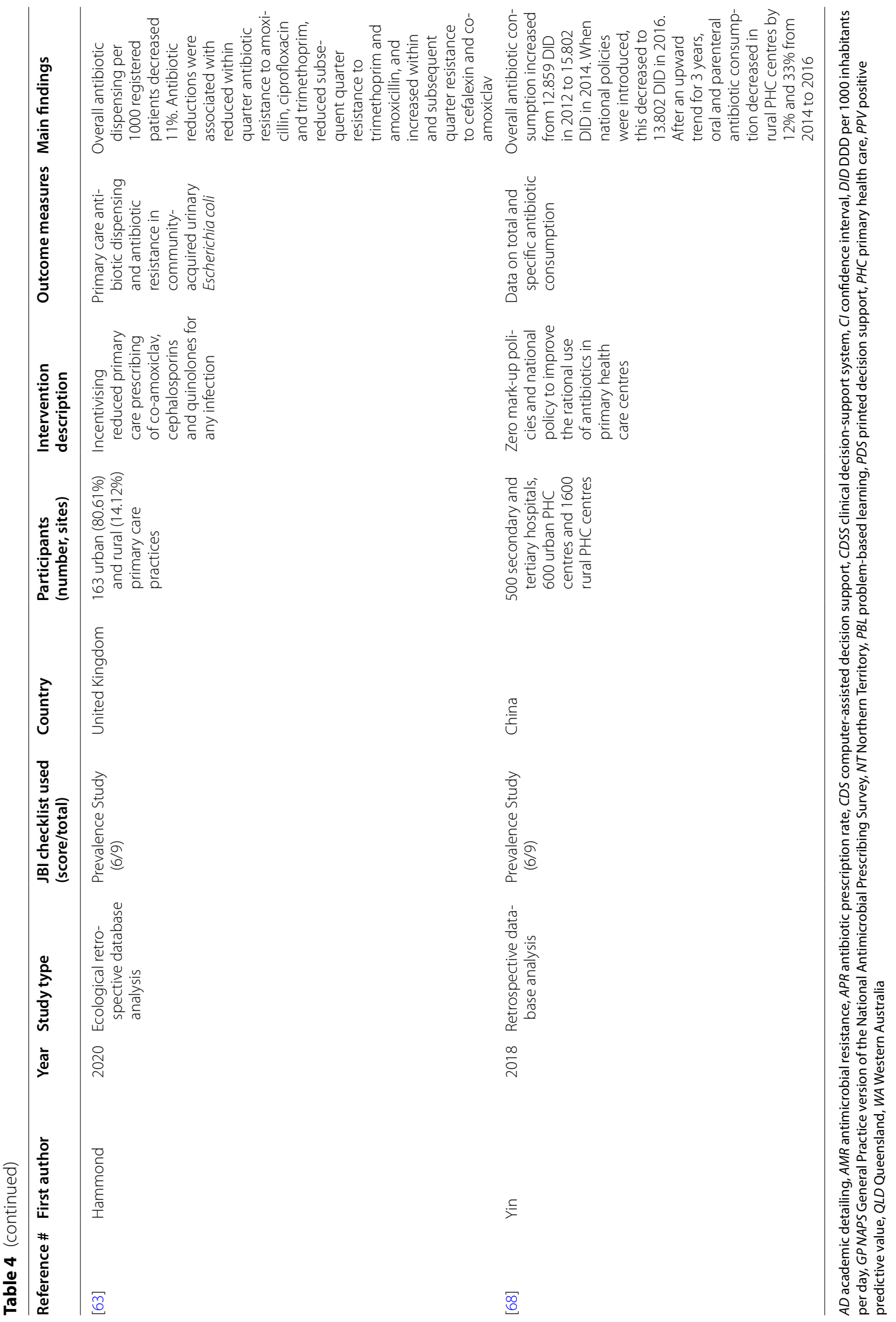




\section{Results}

\section{Study selection process}

The database search identified 253 articles, of which 58 were duplicates. An additional 16 articles were identified through manual searches. The titles and abstracts of 211 articles were screened, with 81 articles excluded due to not meeting the eligibility criteria. Full-text analysis was performed for 130 studies, of which 79 were excluded to yield a final total of 51 articles for inclusion in this review. Reasons of exclusion include irrelevancy to AMS, AMR or antimicrobials in general as well as studies conducted in hospital settings. Figure 1 illustrates the search and selection process.

\section{Correlation of antimicrobial resistance with antibiotic usage and/or volume of antibiotic use}

The link between antimicrobial use and AMR continues from the hospital into the PHC setting, as evidenced by various studies across the globe. An ecologic analysis of data from 20 countries demonstrated that antibiotic use exerted selection pressure that has directly increased the resistance of multiple known pathogenic types of Streptococcus sp. [22]. Similarly, a chart review of Canadian Indigenous communities found methicillin-resistant Staphylococcus aureus (MRSA) to be the organism responsible for over $40 \%$ of skin and soft tissue infections as well as a high prevalence of antibiotic use in these communities, although direct correlations between the two phenomena could not be made [23]. Further evidence can be found in a systematic review by Hansen et al. [24], where immediately following macrolide exposure, resistant bacteria were identified in participants with greater frequency. Although later trends were subsequently met with inconsistency, resistance is regarded as a major adverse effect of macrolide treatment [24]. This is substantiated by a study by Doan et al. [25] involving children below 5 years, in which mass azithromycin administration resulted in up to 7.5 times (95\% confidence interval $[\mathrm{CI}] 3.8-23.1$ ) higher genetic determinants of resistance to macrolides at 48 months. Costelloe et al. [26] demonstrated that antibiotic resistance is highest in the month following treatment, with effects lasting up to a year. This systematic review presented pooled odds ratio (OR) for resistance among urinary tract bacteria of 2.5 (95\% CI 2.1-2.9) and 1.33 (95\% CI 1.2-1.5), and among respiratory tract bacteria of 2.4 (95\% CI 1.4-3.9) and 2.4 (95\% CI 1.3-4.5) within 2 and 12 months of antibiotic treatment, respectively [26].

Prescribing practices in PHC play a major influencing role in AMR rates. Prescription, dispensation and use of penicillin, especially classes susceptible to betalactamase, were associated with increased risks of nasal carriage of resistant S. aureus, with ORs of 1.18 (95\% CI 1.04-1.35) and 1.09 (95\% CI 1.00-1.18) according to two large cross-sectional studies [27, 28]. Azithromycin use was likewise correlated with nasal carriage of $S$. pneumoniae and $S$. aureus strains which are resistant to macrolides $[29,30]$. Hare et al. also discovered a dose-response relationship between azithromycin use and carriage of macrolide-resistant S. pneumoniae and $S$. aureus strains, which were found in $21 \%$ (95\% CI $14-28)$ and $1 \%(95 \%$ CI $0-5)$ respectively when azithromycin was not used, $28 \%$ (95\% CI 17-38) and 14\% (95\% CI 6-22) when azithromycin was used infrequently, and $38 \%$ (95\% CI 26-49) and 23\% (95\% CI 14-33) when azithromycin was used frequently (nptrend $P=0.002$ and $P<0.001$ respectively) [29]. The systematic review by Costelloe et al. [26] accentuated this relationship by drawing associations between multiple or longer durations of antibiotic courses with higher AMR rates, especially for amoxicillin and trimethoprim. However, a randomised controlled trial (RCT) that included 520 children with acute otitis media found that a shorter amoxicillin-clavulanic acid antibiotic regimen of 5 days did not affect AMR rates $(P=0.58)$ and instead, produced less favourable health outcomes with greater likelihood of clinical failure and worse mean symptom scores $(P=0.001)$ compared to the standard 10-day regimen [31]. Nevertheless, this study has limited generalisability due to the age group and disease type [31].

Risks for AMR development are not limited to the specific antimicrobial agent used to treat a particular infection, as suggested in a recent revision of a Cochrane systematic review on the mass treatment of trachoma using antibiotics [32]. Here, evidence shows with high certainty that $S$. pneumoniae, S. aureus and Escherichia coli exhibited approximately fivefold increase in resistance at 12 months not only to agents used to treat trachoma, namely azithromycin and tetracycline, but also to clindamycin despite having no role in trachoma management [32]. Likewise, Doan et al. [25] found that beta-lactam resistance determinants were 2.1 times (95\% CI 1.2-4.0) higher after mass azithromycin distribution. Cross-resistance is a genuine cause for concern, as it expedites the development of multidrug-resistant pathogens, thereby rendering progressively more lines of treatment ineffective.

Overall, the emergence of AMR in the PHC setting has been associated with high-volume antibiotic prescribing and use. Therefore, sustained, large-scale efforts are required to regulate such practices. 


\section{Appropriateness of antimicrobial prescribing in rural and remote primary health care}

Inappropriate prescribing is generally defined as the prescription of antimicrobial agents that do not adhere to authorised guidelines in terms of type of antimicrobial chosen, dose and/or duration, or are deemed unnecessary [33]. In rural and remote areas, inappropriate prescribing was reported to be highly prevalent, with $18-88 \%$ of antimicrobial prescriptions deemed inappropriate depending on the country [34-38]. Antibiotics were the antimicrobial agents most frequently incorrectly prescribed [35-39].

Clinicians in rural and remote $\mathrm{PHC}$ services tended to be high-volume prescribers of antimicrobial agents [40-43]. Antibiotics were prescribed more frequently in rural regions compared to urban areas, $85 \%$ versus 68-80\% respectively [40-42]. Primary health care services in rural and remote areas face additional challenges in the provision of health care, including limited resource allocations and a different patient population compared to urban clinics, which may contribute to differences in prescribing.

An Australian study showed no significant difference in prescribing behaviour and adherence to guidelines between rural- and urban-based physicians [44]. While this study portrayed a positive outlook in Australia, the results cannot be generalised as the focus was on earlycareer general practitioners and urinary tract infections only, and rural practices constituted only $16 \%$ of the study locations [40]. An audit of antimicrobial use in 15 remote PHC clinics across three states in northern Australia found that appropriateness was high compared to general practices in urban settings [45]. Approximately $91 \%, 82 \%$ and $65 \%$ of antimicrobial use in Western Australia, Northern Territory and Queensland adhered to clinical guidelines, endorsed by experts, or constituted agents with the narrowest targets. This appreciably high level of appropriateness was demonstrated by $86 \%$ of nurses and $73 \%$ of doctors in this region [45]. The high rates of appropriateness in this study may be a result of government endorsed clinical guidelines that the nurses are legally bound to comply with in order to prescribe.

Measures of prescribing appropriateness are highly dependent on specific diseases and clinical guidelines used. For example, a study on childhood diarrhoea by Rhee et al. [35] designated the presence of dysentery as the standard for antibiotic prescription, with over-prescription defined as antibiotics given for non-dysentery cases and under-prescription as absence of antibiotics for children with dysentery. In some instances, prescribing appropriateness were inferred directly from antimicrobial use, particularly antibiotics prescriptions for infections not commonly suspected to be of bacterial origin such as acute upper respiratory tract infections [46]. Often, an antimicrobial prescription is deemed appropriate if it is in accordance with local or international therapeutic guidelines designed for that disease entity [35, 44]. Nevertheless, an Australian study assessed both prescribing appropriateness and guideline adherence, which accounted for prescriptions deviating from guidelines for a justified clinical reason [45].

\section{Risk factors associated with inappropriate use/prescribing of antibiotics}

Rurality is often found to be an independent risk factor for inappropriate prescribing [30, 39-41, 47]. Rural and remote areas have widely distributed populations who generally experience poorer health and who are serviced by fewer doctors per population [39]. This invariably translates to increased physician fatigue due to high workloads, which is associated with excessive and errorprone prescribing $[46,48]$. Despite having AMR awareness, rural clinicians were less likely to adopt steps to reduce antibiotic prescriptions, as a survey by Salm et al. [49] suggested.

Aside from the remoteness of practice mentioned above, several other factors contribute to the overuse and misuse of antimicrobials, which ultimately play a major role in the emergence of AMR. Chiefly, physician knowledge and behaviour exert a strong influence on antimicrobial use in the population. Numerous studies have found insufficient awareness of the importance of judicious prescribing and lack of knowledge on local resistance patterns to be major drivers of AMR [38, 47, 50-53]. Most frequently, physicians prescribe antibiotics for viral infections, indicating a substantial need for clinician education $[39,50]$. This problem is not unique among clinicians in rural and remote settings, as those in urban primary care practices share similar knowledge, attitudes and practices $[50,51,53]$.

Although many rural-based physicians commonly recognised the negative consequences of over-prescription, some nevertheless continue to prescribe antimicrobials liberally to patients $[38,51,54]$. This can be due to both internal and external reasons. Doctors cited apprehension of medical complications from undertreatment, perceived patient expectations and intentions to preserve good relations, and the notion that selected prescribed antibiotics would not contribute to resistance as grounds for discrepancy in personal knowledge and clinical practice [38, 51, 52, 54-57]. Concurrently, external pressures including financial considerations in line with incentivising drug sales and patient retention may compel physicians into prescribing inappropriately $[38,52,54]$. System factors such as insufficient accessibility to follow-up as well as the fear of litigation or related medico-legal issues 
were also strong drivers of excessive antibiotic prescribing [51, 54].

Furthermore, attitudes of physicians may influence the development of AMR in rural and remote settings. It is possible that some PHC physicians are complacent, prefer to prescribe by habit, or are reluctant to keep up with new recommendations in prescribing $[47,53]$. Other health care professionals such as pharmacists and informal health providers may contribute to AMR [50, 55] particularly in countries and regions where there is relatively unrestricted access to antimicrobials.

Patient factors are also identified as playing a role in the development of AMR. In particular, non-compliance to prescribed antimicrobial treatments, especially poor adherence to the full course of antibiotics, facilitates the development of AMR in the community $[50,58]$. Treatment decisions are influenced by patient demands, and often driven by unfounded beliefs of obtaining the 'fastest cure' [55]. In some countries and regions where antimicrobial dispensing is not strictly regulated, members of the public may self-prescribe antimicrobial agents for ailments [50, 58-60]. The inappropriate use of antibiotics and demands on clinicians to provide antibiotics may result from a poor understanding of the implications of their misuse, limited access to appropriately trained doctors, scarce resources and limited health literacy $[58,61]$.

Patient attributes associated with inappropriate prescribing and higher AMR rates include patients of a younger age group, female gender, with other co-morbidities and higher socioeconomic status [28, 39]. While further studies are required to elucidate the mechanisms and processes behind these correlations, it is postulated that they could be explained by greater anxiety levels in these populations. For example, parents desire a rapid relief of symptoms for their children, and patients of a higher socioeconomic strata can have greater demands $[40,41]$. Patient expectations in relation to antibiotic treatment was identified by physicians, as placing undue pressure on the prescription of antimicrobials to satisfy patients [57].

\section{Antimicrobial stewardship strategies in remote and rural primary health care settings and their effectiveness}

A total of 16 interventions are included in this section under four distinct themes according to their intervention focus, with further detail outlined in Table 4 . Although the measured outcomes exhibited a high degree of heterogeneity among the studies, a few main groupings can be elucidated from the pooled data, namely rates and appropriateness of antimicrobial prescribing. Nine studies had antimicrobial prescription rates as their primary outcome measure [62-70]. Of these studies, seven had significantly lowered prescription rates post intervention
[62-66, 68-70], in which results ranged from an 11\% decrease when the United Kingdom incentivised reduced prescribing of specific antibiotics [63] to a 49\% drop when a multi-dimensional clinician-focussed intervention was implemented in China [66]. A total of four studies reported on appropriateness of prescribing $[64,67,71$, 72], and all but one-the MIKSTRA study [67] - demonstrated meaningful improvements after intervention.

\section{Health care provider and patient education}

Three publications focused on the provision of education to health care providers, where clinicians and supporting staff received training on antimicrobial prescribing, including implementation of antimicrobial stewardship guidelines and strategies such as delayed prescriptions [65, 67, 73]. Although immediate antibiotic prescription reduced symptom severity and duration of acute otitis media in children by about a day, these benefits were marginal as symptoms were already improving after 24 hours [73]. This study also found that doctors' perception of patient expectations were often overestimated-most parents were satisfied with delayed antibiotic prescribing for their child's illness [73]. A large RCT in rural China implemented a comprehensive clinicianoriented intervention which consisted of clinical guideline implementation/enforcement, monthly reviews on physicians' prescribing rates, training on communication skills and brief education for caregivers [65]. Besides proving to be highly cost-effective [74], this multifaceted education strategy successfully decreased antibiotic prescribing rates for childhood upper respiratory tract infections by $29 \%(P=0.0002)$ at 6 months [65] and up to $36 \%$ $(P<0.0001)$ at 18 months by virtue of improved physician knowledge and communication with patients [66].

On the other hand, modest improvements to antibiotic prescribing were observed in the Finnish MIKSTRA study which promoted the use of first-line treatment for the treatment of acute maxillary sinusitis according to national guidelines recommendations [67]. An education programme using two training methods facilitated by local general practitioners were employed, which were: problem-based learning (PBL) based on group work and an academic detailing (AD) process involving various information sources, feedback and external visits [67]. The RCT only managed to yield minor positive effects on antibiotic prescribing with use of the first-line drug amoxicillin and appropriate duration of antibiotic courses, with the former increasing from 33 to $45 \%$ and 39 to $48 \%$ while the latter increased from 32 to $47 \%$ and 34 to $40 \%$ in PBL and AD centres, respectively. These shortcomings were likely due to various resource issues throughout the trial, which included physician shortages in rural PHCs and improper adherence to guidelines 
brought about by education methods which did not adequately address the local context [67].

Patient education was investigated by a quasi-experiment conducted among Lao villagers by Haenssgen et al. [75] in which a one-off education session involving interactive health-based activities was implemented with mixed results, especially on behavioural change towards antibiotic use. There were noticeable improvements in awareness and understanding of antibiotic resistance, but not attitudes. A combined approach involving education of both the physician and the patient using presentations and printed materials on relevant health information was explored by three studies, all of which showed significant reductions in undesirable outcomes [62, 70, 71]. Chiswell et al. and Belongia et al. decreased antibiotic prescription rates in the rural community, with the former even lowering immediate antibiotic prescriptions from 31.1 to $13.5 \%(P<0.05)[62,70]$. Cummings et al. reduced the proportion of antibiotic-inappropriate prescriptions by $14.9 \%$ (95\% CI $-20.30 \%$ to $-9.05 \%$; $P<0.0001$ ) via distribution of education materials as well as clinician peer comparisons of prescribing behaviour [71].

\section{Physician support systems}

The effectiveness of a clinical-decision support system (CDSS) was researched in two RCTs in rural areas of the United States: Samore et al. [64] and Gonzales et al. [69]. Different implementations of CDSS-based on paper and electronic tools-were employed and compared, and an extension study was performed in the former focussing on a CDSS system based on personal digital assistants [72]. These CDSS-based interventions were effective at mitigating prescriptions for conditions not requiring antibiotics by $32 \%$ in one study [60] and between 11.7 and $13.3 \%$ in the other [69]. CDSS also resulted in an increase of $2.7 \%(P=0.016)$ in provider adherence to guideline recommendations [72].

A cohort study by Madaras-Kelly et al. [76] described an intervention carried out by rural community pharmacists in which patients were interviewed and the prescribing clinicians contacted before dispensing of a broad-spectrum antibiotic. This intervention did not attain favourable responses from the general public [76]; whereby only $7 \%(n=4)$ of participants consented to the pharmacist contacting the prescribing physician to discuss alternative therapies, leading to challenges in performing the intervention to its full extent [76].

\section{Surveillance}

An important component of AMS programmes is comprehensive surveillance of antimicrobial prescribing and resistance which provides data to focus stewardship efforts. Three studies reported on different surveillance tools, which were: a modified General Practice version of the National Antimicrobial Prescribing Survey (GP NAPS) to assess the clinical appropriateness of antimicrobial use according to local Australian guidelines [45]; a mathematical modelling of molecular testing for gonorrhoea resistance surveillance [77]; and the IQVIA Xponent antibiotic database to identify high prescribing physicians [78]. By nature, these studies did not actively involve participants, but rather served to collate relevant data through retrospective data analysis or simulation. All three tools were validated and deemed fit for integration into clinical practice to assist AMS efforts in the future $[45,77,78]$.

\section{National policies}

Achieving AMS on a nationwide scale necessitates upstream policies and regulations, often in regard to financial aspects of prescribing. Two studies by Hammond et al. and Yin et al. provided an overview of the effects of national health policies in the United Kingdom and China, respectively [63, 68]. In 2014/15, reduced prescribing of certain antibiotics in $\mathrm{PHC}$ was incentivised in the UK [63], while China implemented a zero mark-up policy and a national strategy for antibiotic use [68]. In the UK, although overall antibiotic dispensation decreased $11 \%$, the national AMS policy produced mixed results with reduced resistance of community-acquired urinary E. coli to amoxicillin, ciprofloxacin and trimethoprim, but increased resistance to cefalexin and co-amoxiclav [63]. China's strategy lowered the overall antibiotic consumption by $22 \%$ and $8 \%$ for parenteral and oral antibiotics, respectively [68]. The two countries' administrative decisions affected both urban and rural PHC centres, with differences in results between these settings delineated in the Chinese study where antibiotic consumption rates in rural PHCs fell from its peak after in 2014 whereas urban PHCs saw a steady increase in antibiotic use even after policy implementation [63, 68].

\section{Discussion}

There is compelling evidence suggesting that there are direct correlations between excessive antibiotic prescribing and use in the PHC setting with increases in AMR rates in communities across the world. The rurality of practice plays a role in mediating antimicrobial, especially antibiotic, prescribing. Clinicians in rural and remote areas prescribed antimicrobials more frequently and rates of inappropriate prescribing are greater compared to metropolitan counterparts. Factors influencing prescribing behaviours are related to physician knowledge, attitude and behaviour, which are strongly influenced by both intrinsic and extrinsic elements. Patient factors play an important role in the development of AMR, including 


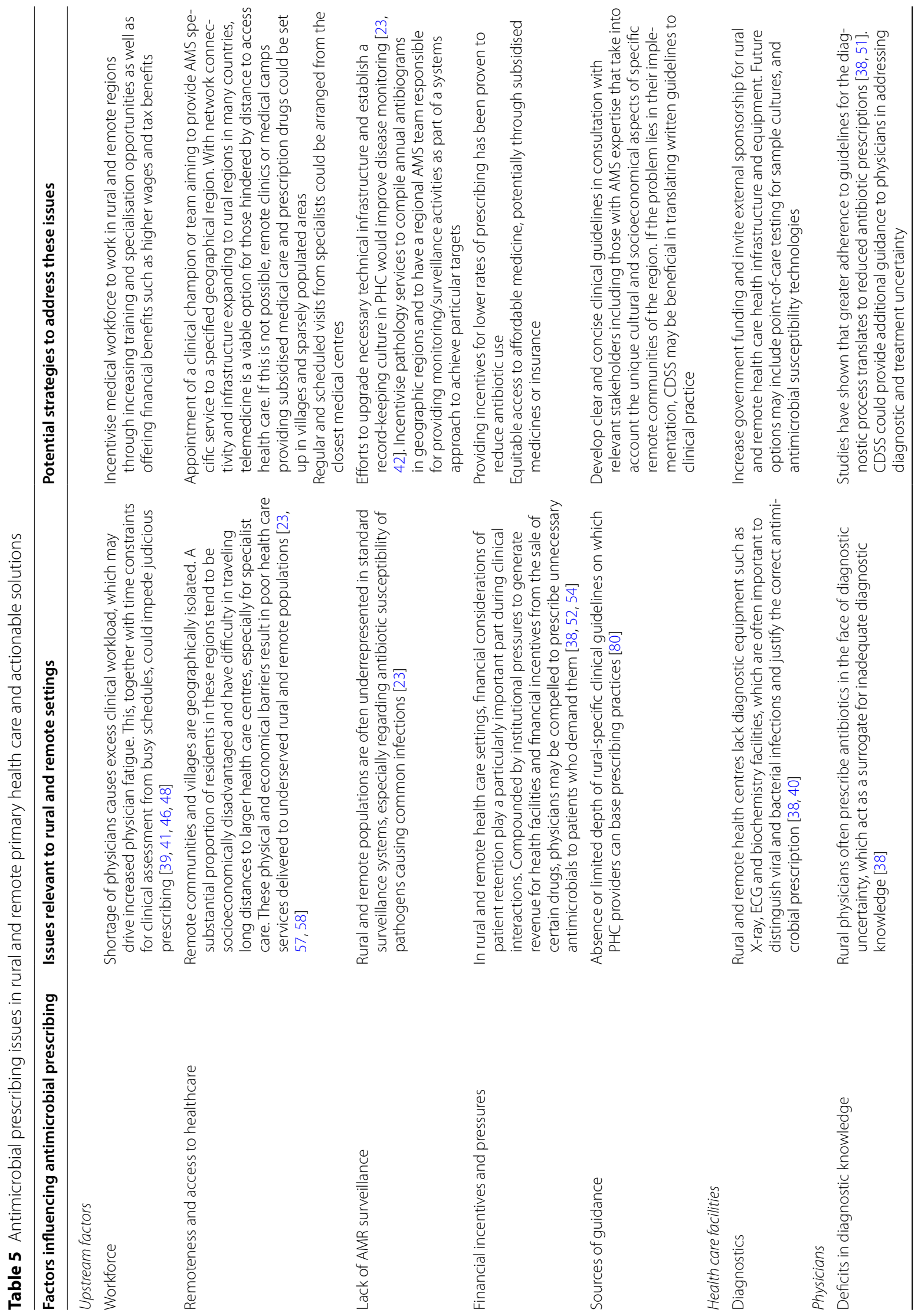




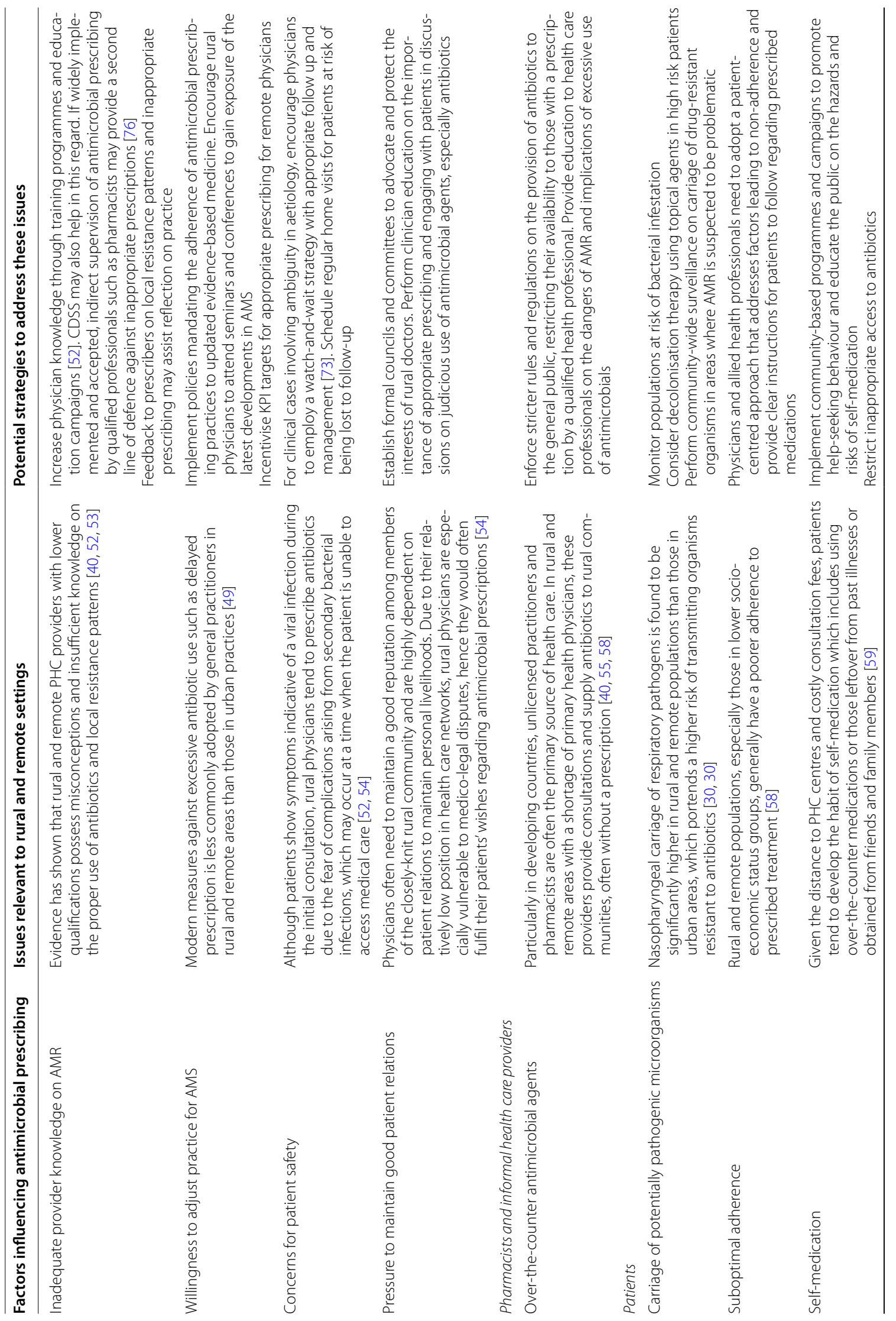




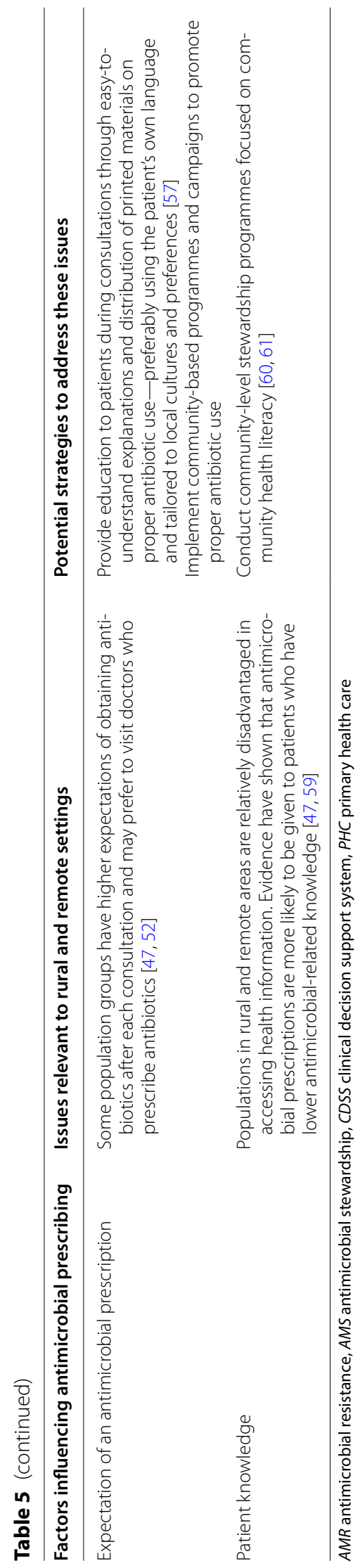


compliance with prescribed treatments, resources, access to healthcare, knowledge, and health literacy.

AMS strategies in the rural and remote PHC settings tend to focus on health care provider and patient education, surveillance, clinician support systems, and nationwide policy changes. These interventions resulted in largely positive outcomes with decreased rates of AMR and improved appropriateness of antimicrobial prescribing. Nonetheless, national stewardship policies also had significant impact, and based on the implementation of other health policies, have greatest impact when there are flow-on state and institutional polices that support practice.

Rural and remote settings present a unique context for PHC delivery. Many aspects can, individually or collectively, lead to inappropriate antimicrobial prescribing in these settings, from upstream factors such as inadequate workforce capacity and financial pressure to circumstances involving health care providers and patients. These factors are summarised in Table 5, together with recommendations on improving AMS implementation.

Previous research has attempted to provide guidance in relation to effective AMS activities to address the specific needs of rural and remote primary health care. Bowen et al. [11] highlighted the challenges of AMS programmes in the context of the Australian Indigenous population and the need to coordinate with relevant sectors such as housing, environmental health and education to improve health-related literacy and infrastructure in order to contain the spread of resistant pathogens. Such a programme should strive to review and improve antimicrobial prescribing and use, apply AMR surveillance data, and inform clinicians and regulatory bodies on judicious antimicrobial use.

In a systematic review of 39 studies in primary care, Arnold et al. [79] found that multifaceted interventions involving educating physicians, patients and the public via a range of different formats across various health care and community settings were most successful in lowering rates of inappropriate antimicrobial prescribing. Although the systematic review included all studies in ambulatory care and not strictly rural or remote settings, it concluded that a single intervention for all contexts does not exist [79]. There is no one-size-fits-all approach to AMS and targeted interventions for specific groups and varied contexts are necessary for effective AMS programmes to prevent AMR emergence.

The review identified several gaps in the literature around AMS in remote and rural PHC. First, the existing research and evidence as to the effectiveness of AMS interventions is quite short-term. Longer term studies, of years rather than week to months, are necessary to increase reliability of findings, given that AMR evolves over a period of time through exchange of genetic material driven by selection pressure [1, 22]. Despite the absence of an all-encompassing AMS intervention, efforts to delineate the most effective components of each intervention would contribute towards developing the best strategy for a given target population. The patient voice, particularly rural and remote populations, is largely absent from the discussion. A greater focus on understanding the patient perspective and investigation of patient understanding of AMR may provide greater success in implementing community-based education programmes. Finally, we acknowledge a distinction exists between rural and remote health [17], but this was not reflected in current literature. Our review involved only five studies on the remote Indigenous community; four in Australia [29, 30, 45, 77] and one in Canada [23]. How AMS strategies differ between rural and remote areas, as well as their applications and significance towards Indigenous populations, warrant further investigation.

\section{Limitations and strengths of this review}

Despite efforts to thoroughly search for and examine articles, this is not a systematic review and a quantitative statistical analysis could not be conducted due to the variability in measured outcomes and target populations. There is a possibility of language bias as the search was limited to the English language. Additionally, all research studies in this field were not covered, especially those conducted prior to the year 2000. Lastly, some of the papers did not separate urban settings from rural and remote settings, so distinct lessons for the rural and remote settings are harder to identify.

Nonetheless, to the best of our knowledge, this is the first structured review to examine AMS in rural and remote PHC. It included a respectable number of studies from around the world. Screening and appraisal of articles were performed by at least two independent researchers, thereby reducing inter-rater variability. Relevant data extracted from studies were categorically summarised in tables for rapid search, thus enabling a comprehensive description of recent evidence on antimicrobial resistance and stewardship in rural and remote PHC settings.

\section{Conclusion}

There is strong evidence that excessive antimicrobial prescribing and use greatly contribute to the rise of AMR. Various physician and patient factors are at play, especially in PHC in remote and rural settings where health resources and regulations are limited. Several AMS strategies aimed at education, clinical support, surveillance, and policies have been attempted with mostly positive results. Future researchers should place emphasis 
on investigating the effectiveness of interventions over longer durations, capturing the patient perspective and contrasting AMS in rural and remote settings.

\begin{abstract}
Abbreviations
AD: Academic detailing; AMR: Antimicrobial resistance; AMS: Antimicrobial stewardship; CDSS: Clinical-decision support system; Cl: Confidence interval; GP NAPS: General Practice version of the National Antimicrobial Prescribing Survey; MMM: Modified mondahs model; MRSA: Methicillin-resistant Staphylococcus aureus; OR: Odds ratio; PBL: Problem-based learning; PHC: Primary health care; RCT: Randomised controlled trial.
\end{abstract}

\section{Supplementary Information}

The online version contains supplementary material available at https://doi. org/10.1186/s13756-021-00964-1.

Additional file 1. Critical appraisal of included articles based on Joanna Briggs Institute (JBI) checklists.

\section{Acknowledgements}

Not applicable.

\section{Authors' contributions}

All authors conceived of the project, it's design and scope; JWY and SMT retrieved all articles and drafted the manuscript. All authors read and approved the final manuscript.

\section{Funding}

No funding provided for this project.

\section{Availability of data and materials}

All data generated or analysed during this study are included in this published article (and its Additional file 1).

\section{Declarations}

\section{Ethics approval and consent to participate}

Not applicable — narrative review using publicly available data.

\section{Consent for publication}

Not applicable.

\section{Competing interests}

The authors declare that they have no competing interests.

\section{Author details}

${ }^{1}$ Jeffrey Cheah School of Medicine and Health Sciences, Monash University Malaysia, 47500 Bandar Sunway, Malaysia. ${ }^{2}$ Flinders University- Rural and Remote Health NT, Royal Darwin Hospital Campus, Rocklands Drive, Tiwi, NT 0810, Australia. ${ }^{3}$ Alice Springs Hospital, Central Australian Health Service, Alice Springs, NT 0870, Australia. ${ }^{4}$ University of Queensland Centre for Clinical Research, The University of Queensland, Brisbane, QLD, Australia.

Received: 18 March 2021 Accepted: 28 May 2021

Published online: 13 July 2021

\section{References}

1. Marston HD, Dixon DM, Knisely JM, Palmore TN, Fauci AS. Antimicrobial resistance. JAMA. 2016;316(11):1193-204.

2. Australian Commission on Safety and Quality in Health Care. AURA 2019: third Australian report on antimicrobial use and resistance in human health Sydney: ACSQHC; 2019 [24 Feb 2021]. https://www.safetyandq uality.gov.au/sites/default/files/2019-06/AURA-2019-Report.pdf.
3. Australian Department of Health and Department of Agriculture. Australia's National Antimicrobial Resistance Strategy-2020 and Beyond: Australian Government; 2020 [updated 13 March 202025 Jan 2021]. https://www.amr.gov.au/file/1398/download?token=NLVVTd_j.

4. World Health Organisation. Global action plan on antimicrobial resistance 2015 [8 Feb 2021]. https://apps.who.int/iris/bitstream/handle/10665/ 193736/9789241509763_eng.pdf?sequence=1.

5. European Centre for Disease Prevention and Control. Strategies and action plans for antimicrobial resistance 2020 [8 Feb 2021]. https://www. ecdc.europa.eu/en/publications-data/directory-guidance-preventionand-control/antimicrobial-resistance-strategies.

6. US Government Federal Task Force on Combating Antibiotic-Resistant Bacteria. National action plan for combating antibiotic-resistant bacteria 2020-2025 2020 [8 Feb 2021]. https://aspe.hhs.gov/system/files/pdf/ 264126/CARB-National-Action-Plan-2020-2025.pdf.

7. Dyar OJ, Huttner B, Schouten J, Pulcini C. What is antimicrobial stewardship? Clin Microbiol Infect. 2017;23(11):793-8.

8. Australian Commission on Safety and Quality in Health Care. Antimicrobial Stewardship in Australian Health Care 2018 Sydney: ACSQHC; 2018 [23 Feb 2021]. https://www.safetyandquality.gov.au/sites/default/files/ 2020-10/complete_ams_book_oct_2020_incl_13_14_new_contents_ new_gloss.pdf.

9. Plachouras D, Hopkins S. Antimicrobial stewardship: we know it works; time to make sure it is in place everywhere. Cochrane Database Syst Rev. 2017;2(9).

10. World Health Organization. Antimicrobial resistance and primary health care 2018 [29 Jan 2021]. https://apps.who.int/iris/bitstream/handle/ 10665/326454/WHO-HIS-SDS-2018.56-eng.pdf.

11. Bowen AC, Daveson K, Anderson L, Tong SY. An urgent need for antimicrobial stewardship in Indigenous rural and remote primary health care. Med J Aust. 2019:211(1):9-11.e1.

12. Strasser R. Rural health around the world: challenges and solutions. Fam Pract. 2003;20(4):457-63.

13. Wakerman J, Humphreys JS, Wells R, Kuipers P, Entwistle P, Jones J. Primary health care delivery models in rural and remote Australia: a systematic review. BMC Health Serv Res. 2008;8:276.

14. Department of Health. Modified Monash Model (MMM) 2019. http:// www.ga.gov.au/place-names/PlaceDetails.jsp?submit1=GA1; 2019.

15. Statistics ABo. The Australian Statistical Geography Standard remoteness structure: Australian Bureau of Statistics; (n.d.). https://www.abs.gov.au/ websitedbs/d3310114.nsf/home/remoteness+structure.

16. Wakerman J, Humphreys JS. Rural and remote health-definitions, policy and priorities. In: Liaw S, Kilpatrick S, editors. A textbook of Australian rural health. Canberra: Australian Rural Health Education Network; 2008. p. 13-30.

17. Bourke L, Humphreys JS, Wakerman J, Taylor J. Understanding rural and remote health: a framework for analysis in Australia. Health Place. 2012;18(3):496-503.

18. Brundisini F, Giacomini M, DeJean D, Vanstone M, Winsor S, Smith A Chronic disease patients' experiences with accessing health care in rural and remote areas: a systematic review and qualitative meta-synthesis. Ont Health Technol Assess Ser. 2013;13(15):1-33.

19. Australian Institute of Health and Welfare. Rural \& remote health 2019 [updated 22 Oct 2019. https://www.aihw.gov.au/reports/rural-remoteaustralians/rural-remote-health/contents/access-to-health-care.

20. Cuningham W, McVernon J, Lydeamore MJ, Andrews RM, Carapetis J, Kearns T, et al. High burden of infectious disease and antibiotic use in early life in Australian Aboriginal communities. Aust N Z J Public Health. 2019;43(2):149-55.

21. Cameron JK, Hall L, Tong SYC, Paterson DL, Halton K. Incidence of community onset MRSA in Australia: least reported where it is Most prevalent. Antimicrob Resist Infect Control. 2019;8(1):33.

22. Albrich WC, Monnet DL, Harbarth S. Antibiotic selection pressure and resistance in Streptococcus pneumoniae and Streptococcus pyogenes. Emerg Infect Dis. 2004;10(3):514-7.

23. Jeong D, Nguyen HNT, Tyndall M, Schreiber YS. Antibiotic use among twelve Canadian First Nations communities: a retrospective chart review of skin and soft tissue infections. BMC Infect Dis. 2020;20(1):118.

24. Hansen MP, Scott AM, McCullough A, Thorning S, Aronson JK, Beller EM, et al. Adverse events in people taking macrolide 
antibiotics versus placebo for any indication. Cochrane Database Syst Rev. 2019;1 (1):CD011825-CD.

25. Doan T, Worden L, Hinterwirth A, Arzika AM, Maliki R, Abdou A, et al. Macrolide and nonmacrolide resistance with mass azithromycin distribution. N Engl J Med. 2020;383(20):1941-50.

26. Costelloe C, Metcalfe C, Lovering A, Mant D, Hay AD. Effect of antibiotic prescribing in primary care on antimicrobial resistance in individual patients: systematic review and meta-analysis. BMJ. 2010;340:c2096.

27. Boada A, Pons-Vigués M, Real J, Grezner E, Bolíbar B, Llor C. Previous antibiotic exposure and antibiotic resistance of commensal Staphylococcus aureus in Spanish primary care. Eur J Gen Pract. 2018;24(1):125-30.

28. van Bijnen EM, Paget J, de Lange-de Klerk ES, den Heijer CD, Versporten A, Stobberingh EE, et al. Antibiotic exposure and other risk factors for antimicrobial resistance in nasal commensal Staphylococcus aureus: an ecological study in 8 European Countries. PLoS ONE. 2015;10(8):e0135094.

29. Hare KM, Singleton RJ, Grimwood K, Valery PC, Cheng AC, Morris PS, et al. Longitudinal nasopharyngeal carriage and antibiotic resistance of respiratory bacteria in indigenous Australian and Alaska native children with bronchiectasis. PLoS ONE. 2013;8(8):e70478.

30. Hare KM, Grimwood K, Chang AB, Chatfield MD, Valery PC, Leach AJ, et al. Nasopharyngeal carriage and macrolide resistance in Indigenous children with bronchiectasis randomized to long-term azithromycin or placebo. Eur J Clin Microbiol Infect Dis. 2015;34(11):2275-85.

31. Hoberman A, Paradise JL, Rockette HE, Kearney DH, Bhatnagar S, Shope TR, et al. Shortened antimicrobial treatment for acute otitis media in young children. N Engl J Med. 2016;375(25):2446-56.

32. Evans JR, Solomon AW, Kumar R, Perez Á, Singh BP, Srivastava RM, et al. Antibiotics for trachoma. Cochrane Database Syst Rev. 2019;9:CD001860.

33. Smith DRM, Dolk FCK, Pouwels KB, Christie M, Robotham JV, Smieszek T. Defining the appropriateness and inappropriateness of antibiotic prescribing in primary care. J Antimicrob Chemother 2018;73(suppl_2):ii1 1-8.

34. Giles AB, Sarbacker GB, Anderson K, King C, Goodbar N, Shealy K. Evaluation of antibiotic utilization in a rural, outpatient clinic: an antimicrobial stewardship initiative. J Pharm Pract. 2019:897190019896498.

35. Rhee C, Aol G, Ouma A, Audi A, Muema S, Auko J, et al. Inappropriate use of antibiotics for childhood diarrhea case management-Kenya, 2009-2016. BMC Public Health. 2019;19(3):468.

36. Sarwar MR, Saqib A, Iftikhar S, Sadiq T. Antimicrobial use by WHO methodology at primary health care centers: a cross sectional study in Punjab, Pakistan. BMC Infect Dis. 2018;18(1):492.

37. Wang J, Wang P, Wang X, Zheng Y, Xiao Y. Use and prescription of antibiotics in primary health care settings in China. JAMA Intern Med. 2014;174(12):1914-20.

38. Xue H, Shi Y, Huang L, Yi H, Zhou H, Zhou C, et al. Diagnostic ability and inappropriate antibiotic prescriptions: a quasi-experimental study of primary care providers in rural China. J Antimicrob Chemother. 2019;74(1):256-63.

39. Singer A, Fanella S, Kosowan L, Falk J, Dufault B, Hamilton K, et al. Informing antimicrobial stewardship: factors associated with inappropriate antimicrobial prescribing in primary care. Fam Pract. 2018;35(4):455-60.

40. Kumar R, Indira K, Rizvi A, Rizvi T, Jeyaseelan L. Antibiotic prescribing practices in primary and secondary health care facilities in Uttar Pradesh, India. J Clin Pharm Ther. 2008;33(6):625-34.

41. Kumari Indira KS, Chandy SJ, Jeyaseelan L, Kumar R, Suresh S. Antimicrobial prescription patterns for common acute infections in some rural \& urban health facilities of India. Indian J Med Res. 2008;128(2):165-71.

42. Kwiatkowska R, Shen X, Lu M, Cheng J, Hickman M, Lambert H, et al. Patients without records and records without patients: review of patient records in primary care and implications for surveillance of antibiotic prescribing in rural China. BMC Health Serv Res. 2020;20(1):564.

43. Staub MB, Ouedraogo Y, Evans CD, Katz SE, Talley PP, Kainer MA, et al. Analysis of a high-prescribing state's 2016 outpatient antibiotic prescriptions: implications for outpatient antimicrobial stewardship interventions. Infect Control Hosp Epidemiol. 2020;41(2):135-42.

44. Davey A, Tapley A, Mulquiney K, van Driel M, Fielding A, Holliday E, et al. Management of urinary tract infection by early-career general practitioners in Australia. J Eval Clin Pract. 2020;26(6):1703-10.

45. Cuningham W, Anderson L, Bowen AC, Buising K, Connors C, Daveson $\mathrm{K}$, et al. Antimicrobial stewardship in remote primary healthcare across northern Australia. PeerJ. 2020;8:e9409-e.
46. Silverman M, Povitz M, Sontrop JM, Li L, Richard L, Cejic S, et al. Antibiotic prescribing for nonbacterial acute upper respiratory infections in elderly persons. Ann Intern Med. 2017;166(11):765-74.

47. Wang D, Liu C, Zhang X, Liu C. Identifying antibiotic prescribing patterns through multi-level latent profile analyses: a cross-sectional survey of primary care physicians. Front Pharmacol. 2020;11:591709.

48. Yuguero O, Marsal JR, Esquerda M, Galvan L, Soler-González J. Crosssectional study of the association between empathy and burnout and drug prescribing quality in primary care. Prim Health Care Res Dev. 2019;20:e145

49. Salm F, Schneider S, Schmücker K, Petruschke I, Kramer TS, Hanke R, et al. Antibiotic prescribing behavior among general practitioners-a questionnaire-based study in Germany. BMC Infect Dis. 2018;18(1):208.

50. Al-Homaidan HT, Barrimah IE. Physicians'knowledge, expectations, and practice regarding antibiotic use in primary health care. Int J Health Sci (Qassim). 2018;12(3):18-24.

51. Dallas $A$, van Driel $M$, van de Mortel $T$, Magin P. Antibiotic prescribing for the future: exploring the attitudes of trainees in general practice. $\mathrm{Br} J \mathrm{Gen}$ Pract. 2014;64(626):e561-7.

52. Zhang Z, Zhan X, Zhou H, Sun F, Zhang H, Zwarenstein M, et al. Antibiotic prescribing of village doctors for children under 15 years with upper respiratory tract infections in rural China: a qualitative study. Medicine (Baltimore). 2016;95(23):e3803.

53. Duane S, Domegan C, Callan A, Galvin S, Cormican M, Bennett K, et al. Using qualitative insights to change practice: exploring the culture of antibiotic prescribing and consumption for urinary tract infections. BMJ Open. 2016;6(1):e008894.

54. Chen M, Kadetz P, Cabral C, Lambert H. Prescribing antibiotics in rural China: the influence of capital on clinical realities. Front Sociol. 2020;5:66.

55. Nair M, Tripathi S, Mazumdar S, Mahajan R, Harshana A, Pereira A, et al. "Without antibiotics, I cannot treat": a qualitative study of antibiotic use in Paschim Bardhaman district of West Bengal, India. PLoS ONE. 2019;14(6):e0219002.

56. Wood F, Simpson S, Butler CC. Socially responsible antibiotic choices in primary care: a qualitative study of GPs' decisions to prescribe broadspectrum and fluroquinolone antibiotics. Fam Pract. 2007;24(5):427-34.

57. Fletcher-Lartey S, Yee M, Gaarslev C, Khan R. Why do general practitioners prescribe antibiotics for upper respiratory tract infections to meet patient expectations: a mixed methods study. BMJ Open. 2016;6(10):012244.

58. Barker AK, Brown K, Ahsan M, Sengupta S, Safdar N. Social determinants of antibiotic misuse: a qualitative study of community members in Haryana, India. BMC Public Health. 2017;17(1):333.

59. Chai J, Coope C, Cheng J, Oliver I, Kessel A, Hu Z, et al. Cross-sectional study of the use of antimicrobials following common infections by rural residents in Anhui, China. BMJ Open. 2019;9(4):e024856.

60. Collins JM, Dennis EE, Green MW, Greene EM. Patient self-prescription and antimicrobial stewardship: considerations for primary care. J Am Pharm Assoc. 2020;60(5):e40-3.

61. Salm F, Ernsting C, Kuhlmey A, Kanzler M, Gastmeier P, Gellert P. Antibiotic use, knowledge and health literacy among the general population in Berlin, Germany and its surrounding rural areas. PLoS ONE. 2018;13(2):e0193336.

62. Chiswell E, Hampton D, Okoli CTC. Effect of patient and provider education on antibiotic overuse for respiratory tract infections. J Healthc Qual. 2019;41(3):e13-20.

63. Hammond A, Stuijfzand B, Avison MB, Hay AD. Antimicrobial resistance associations with national primary care antibiotic stewardship policy: primary care-based, multilevel analytic study. PLOS ONE. 2020;15(5):e0232903.

64. Samore MH, Bateman K, Alder SC, Hannah E, Donnelly S, Stoddard GJ et al. Clinical decision support and appropriateness of antimicrobial prescribing: a randomized trial. JAMA. 2005;294(18):2305-14.

65. Wei X, Zhang Z, Walley JD, Hicks JP, Zeng J, Deng S, et al. Effect of a training and educational intervention for physicians and caregivers on antibiotic prescribing for upper respiratory tract infections in children at primary care facilities in rural China: a cluster-randomised controlled trial. Lancet Glob Health. 2017;5(12):e1258-67.

66. Wei X, Zhang Z, Hicks JP, Walley JD, King R, Newell JN, et al. Long-term outcomes of an educational intervention to reduce antibiotic prescribing for childhood upper respiratory tract infections in rural China: follow-up of a cluster-randomised controlled trial. PLoS Med. 2019;16(2):e1002733. 
67. Varonen H, Rautakorpi U-M, Nyberg S, Honkanen PO, Klaukka T, Palva $E$, et al. Implementing guidelines on acute maxillary sinusitis in general practice-a randomized controlled trial. Fam Pract. 2007;24(2):201-6.

68. Yin J, Li Q, Sun Q. Antibiotic consumption in Shandong Province, China: an analysis of provincial pharmaceutical centralized bidding procurement data at public healthcare institutions, 2012-16. J Antimicrob Chemother. 2018;73(3):814-20.

69. Gonzales R, Anderer T, McCulloch CE, Maselli JH, Bloom FJ Jr, Graf TR, et al. A cluster randomized trial of decision support strategies for reducing antibiotic use in acute bronchitis. JAMA Intern Med. 2013;173(4):267-73.

70. Belongia EA, Sullivan BJ, Chyou PH, Madagame E, Reed KD, Schwartz B. A community intervention trial to promote judicious antibiotic use and reduce penicillin-resistant Streptococcus pneumoniae carriage in children. Pediatrics. 2001;108(3):575-83.

71. Cummings PL, Alajajian R, May LS, Grant R, Greer H, Sontz J, et al. Utilizing behavioral science to improve antibiotic prescribing in rural urgent care settings. Open Forum Infect Dis. 2020;7(7):ofaa174.

72. Rubin MA, Bateman K, Donnelly S, Stoddard GJ, Stevenson K, Gardner RM, et al. Use of a personal digital assistant for managing antibiotic prescribing for outpatient respiratory tract infections in rural communities. J Am Med Inform Assoc. 2006;13(6):627-34.

73. Little P, Gould C, Williamson I, Moore M, Warner G, Dunleavey J. Pragmatic randomised controlled trial of two prescribing strategies for childhood acute otitis media. BMJ. 2001;322(7282):336.

74. Zhang Z, Dawkins B, Hicks JP, Walley JD, Hulme C, Elsey H, et al. Costeffectiveness analysis of a multi-dimensional intervention to reduce inappropriate antibiotic prescribing for children with upper respiratory tract infections in China. Trop Med Int Health. 2018;23(10):1092-100.
75. Haenssgen MJ, Xayavong T, Charoenboon N, Warapikuptanun P, Khine $Z Y$. The consequences of AMR education and awareness raising: outputs, outcomes, and behavioural impacts of an antibiotic-related educational activity in Lao PDR. Antibiotics (Basel). 2018;7(4):95.

76. Madaras-Kelly KJ, Hannah EL, Bateman K, Samore MH. Experience with a clinical decision support system in community pharmacies to recommend narrow-spectrum antimicrobials, nonantimicrobial prescriptions, and OTC products to decrease broad-spectrum antimicrobial use. J Manag Care Pharm. 2006;12(5):390-7.

77. Hui BB, Ryder N, Su JY, Ward J, Chen MY, Donovan B, et al. Exploring the benefits of molecular testing for Gonorrhoea antibiotic resistance surveillance in remote settings. PLOS ONE. 2015;10(7):e0133202.

78. Schwartz KL, Chen C, Langford BJ, Brown KA, Daneman N, Johnstone J, et al. Validating a popular outpatient antibiotic database to reliably identify high prescribing physicians for patients 65 years of age and older. PLOS ONE. 2019;14(9):e0223097.

79. Arnold SR, Straus SE. Interventions to improve antibiotic prescribing practices in ambulatory care. Cochrane Database Syst Rev. 2005;2005(4):Cd003539.

80. Reynolds L, McKee M. Factors influencing antibiotic prescribing in China: an exploratory analysis. Health Policy. 2009;90(1):32-6.

\section{Publisher's Note}

Springer Nature remains neutral with regard to jurisdictional claims in published maps and institutional affiliations.
Ready to submit your research? Choose BMC and benefit from:

- fast, convenient online submission

- thorough peer review by experienced researchers in your field

- rapid publication on acceptance

- support for research data, including large and complex data types

- gold Open Access which fosters wider collaboration and increased citations

- maximum visibility for your research: over 100M website views per year

At BMC, research is always in progress.

Learn more biomedcentral.com/submissions 